\title{
Expedition 310 summary
}

\author{
Expedition 310 Scientists $^{2}$
}

\section{Chapter contents}

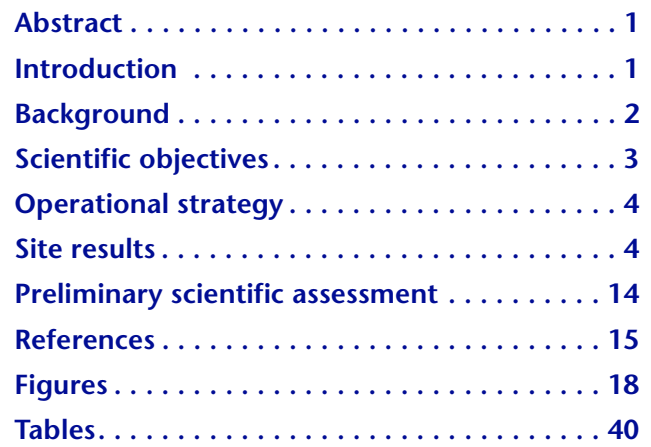

${ }^{1}$ Expedition 310 Scientists, 2007. Expedition 310 summary. In Camoin, G.F., Iryu, Y., McInroy, D.B., and the Expedition 310 Scientists. Proc. IODP, 310: Washington, DC (Integrated Ocean Drilling Program Management International, Inc.). doi:10.2204/iodp.proc.310.101.2007 'Expedition 310 Scientists' addresses.

\section{Abstract}

Integrated Ocean Drilling Program (IODP) Expedition 310 to the reef terraces around Tahiti, French Polynesia, was the second expedition to utilize a mission-specific platform and was conducted by the European Consortium for Ocean Research Drilling (ECORD) Science Operator (ESO). The objectives of Expedition 310 are to establish the course of last deglacial sea level rise at Tahiti, to define sea-surface temperature variations for the region over the period 20,000-10,000 cal. y BP, and to analyze the impact of sea level changes on reef growth and geometry. To meet these objectives, the last deglacial reef sequence, which consists of successive reef terraces seaward of the living barrier reef, was cored from a dynamically positioned vessel during October and November 2005. A total of 37 boreholes at 22 sites were cored in water depths ranging from 41.65 to $117.54 \mathrm{~m}$. Borehole logging operations in ten boreholes at seven sites provided continuous geophysical information about the drilled strata. Cores were described during the Onshore Science Party at the IODP Bremen Core Repository during February and March 2006, where minimum and some standard measurements were made. Further postcruise research on samples taken during the Onshore Science Party is expected to fulfill the objectives of the expedition.

\section{Introduction}

The timing and course of the last deglaciation is generally considered to be an essential component for understanding the dynamics of large ice sheets (Lindstrom and MacAyeal, 1993) and their effects on Earth's isostasy (Lambeck, 1993; Peltier, 1994). Moreover, the disappearance of glacial ice sheets was responsible for dramatic changes in the freshwater fluxes to the oceans, which disturbed the general thermohaline circulation and, hence, global climate (e.g., Stocker and Wright, 1991). Coral reefs, like the one that surrounds Tahiti, are excellent sea level indicators, and their accurate dating by mass spectrometry is of prime importance for determining the timing of deglaciation events and thus for understanding the mechanisms driving glacial-interglacial cycles. Furthermore, scleractinian coral colonies can monitor and record past sea-surface temperatures (SSTs). 


\section{Background}

\section{Sea level changes as global climate indicator}

Only three deglaciation curves based on coral reef records have been accurately dated for times reaching the Pleistocene/Holocene boundary: in Barbados between 19,000 and 8,000 cal. y BP (Fairbanks, 1989; Bard et al., 1990a, 1990b), in New Guinea between 13,000 and 6,000 cal. y BP (Chappell and Polach, 1991; Edwards et al., 1993), and in Tahiti between $13,750 \mathrm{cal}$. y BP and $2,380{ }^{14} \mathrm{C}$ y BP (Bard et al., 1996) (Fig F1). So far, the Barbados curve is the only one to encompass the whole deglaciation because it is based on offshore drilling. However, this site, like New Guinea, is located in an active subduction zone where tectonic movements can be large and discontinuous, so the apparent sea level records may be biased by variations in the rates of tectonic uplift. Hence, there is a clear need to study past sea level changes in tectonically stable regions or in areas where the vertical movements are slow and/or regular.

The Barbados record suggested that the last deglaciation was characterized by two brief periods of accelerated melting superimposed on a smooth and continuous rise of sea level with no reversals (Fig F1). These so-called meltwater pulse (MWP) events (MWP-1A and MWP-1B at 13,800 and 11,300 cal. y $\mathrm{BP}$, respectively) are thought to correspond to massive inputs of continental ice to the oceans (i.e., $~ 50-$ $40 \mathrm{~mm} / \mathrm{y}$, roughly equivalent to annual discharge rates of $16,000 \mathrm{~km}^{3}$ for MWP-1A). MWP-1A corresponds to a short and intense cooling period between 14,100 and 13,900 cal. y BP in Greenland records (Johnsen et al., 1992; Grootes et al., 1993) and therefore postdates initiation of the BöllingAlleröd warm period at $14,900-14,700$ cal. y BP (Broecker, 1992). The sea level jump evidenced in New Guinea at 11,000 cal. y BP (Edwards et al., 1993) is delayed by a few centuries when compared to that observed at Barbados. These two meltwater pulses are thought to have induced reef-drowning events (Blanchon and Shaw, 1995). Two "give-up" reef levels have been reported at 90-100 and 55-65 m water depth on the Mayotte foreslopes (Comoro Islands) and have been related to the Bölling and the postYounger Dryas meltwater pulses (Dullo et al., 1998); similar features are recorded in the southern Great Barrier Reef (GBR) (Troedson and Davies, 2001) and in the Caribbean (MacIntyre et al., 1991; Grammer and Ginsburg, 1992). A third Acropora reef-drowning event at $\sim 7600$ cal. y BP has been assumed by Blanchon and Shaw (1995).
However, there are still some doubts concerning the general pattern of sea level rise during the last deglaciation events, including the amplitude of the maximum lowstand during the Last Glacial Maximum (LGM) and the occurrence of increased glacial meltwater with resultant accelerated sea level rise (Broecker, 1990). Furthermore, sawtooth sea level fluctuations between 19,000 and 15,280 cal. y BP (Locker et al., 1996) and a sea level fall coeval with climatic changes at $\sim 11,000$ cal. y BP are still controversial topics.

Worldwide sea level compilations indicate that local sea level histories varied considerably around the world in relation to both postglacial redistribution of water masses and a combination of local processes (Lambeck, 1993; Peltier, 1994), although significant deviations between model predictions and field data have been noted in several regions (Camoin et al., 1997). The last deglacial sea level changes at sites located far away from glaciated regions ("far field") provide basic information regarding the melting history of continental ice sheets and the rheological structure of Earth. The effect of hydroisostasy depends on the size of the islands: for very small islands, the addition of meltwater produces a small differential response between the island and the seafloor, whereas the meltwater load produces significant differential vertical movement between larger islands or continental margins and the seafloor (Lambeck, 1993). There is, therefore, a need to establish the validity of such effects at two ideal sites located at a considerable distance from the major former ice sheets: (1) on a small oceanic island and (2) on a continental margin. In both cases, it is essential for the sites chosen that the tectonic signal is small or regular within the short time period proposed for investigation so that rigorous tests of proposed Northern and Southern Hemisphere deglaciation curves from Barbados and New Guinea can be made. Two such places were proposed: Tahiti and the GBR. This expedition conducted investigations at Tahiti sites only.

\section{Climatic and oceanographic changes during last deglaciation events}

The results of the Long-Range Investigation, Mapping, and Prediction (CLIMAP) program suggested that LGM tropical SSTs were similar to modern ones. However, this interpretation is not consistent with snowline reconstructions and paleobotanic data (Rind and Peteet, 1985; Anderson and Webb, 1994).

The available $\mathrm{Sr} / \mathrm{Ca}$ and U/Ca data from coral reef areas report SSTs $5^{\circ} \mathrm{C}$ colder than those of today during the LGM and $2^{\circ} \mathrm{C}$ lower at $\sim 10,000-9,000$ cal. y BP at 
Barbados (Guilderson et al., 1994), whereas studies in the west Pacific indicate that the full amplitude of the glacial-Holocene temperature change may have ranged between $3^{\circ}$ and $6^{\circ} \mathrm{C}$ (McCulloch et al., 1996; Beck et al., 1997; Gagan et al., 1998) (Fig F1). Troedson and Davies (2001) define SSTs immediately south of the GBR some $4.5^{\circ} \mathrm{C}$ colder during the LGM and $1^{\circ} \mathrm{C}$ colder at 10,000 cal. y BP. This casts doubt upon the phase shift of $3000 \mathrm{y}$ for climate changes between the two hemispheres that was assumed by Beck et al. (1997), in clear distinction from the apparent synchronism of the last deglaciation, inferred from various sources (i.e., coral records, ice cores, snowline reconstructions, vegetation records, and alkenone palaeothermometry) (Bard et al., 1997).

Coral-based climate studies have successfully been used to document Holocene climatic variations. SSTs warmer by $1^{\circ} \mathrm{C}$, monsoonal rainfall, and possibly weaker El Niño-Southern Oscillation (ENSO) at $\sim 58,000$ cal. y BP in eastern Australia have been deduced from isotopic and $\mathrm{Sr} / \mathrm{Ca}$ high-resolution measurements on corals from the central GBR (Gagan et al., 1998). An ENSO-like cyclic climatic variation with a return period of 3-5 y has been evidenced in a 4150 cal. y BP coral from the Seychelles, although the intensity of the annual decrease in SSTs caused by monsoonal cooling was lower than that of today (Zinke et al., 2005).

Additional information is required for a better understanding of climatic conditions in tropical regions during the last deglaciation. In these areas, the most debated points are twofold: (1) the quantification of SSTs and the identification of related climatic variations during the last deglaciation events and (2) the timing of the relevant last deglacial warming in the two hemispheres.

\section{Scientific objectives}

\section{Establish the course of postglacial sea level rise at Tahiti (i.e., define the exact shape of the deglaciation curve for the period 20,000 10,000 cal. y BP).}

In establishing the deglaciation curve, we hope to assess the validity, timing, and amplitude of the MWP$1 \mathrm{~A}$ event, assess the maximum sea level drop during the LGM to prove or disprove the sawtooth pattern of sea level rise during the last deglaciation (Locker et al., 1996), and test predictions based on different ice and rheological models.

Reconstruction of sea level curves relies on absolute dating of in situ corals by radiometric methods $\left({ }^{230} \mathrm{Th} /{ }^{234} \mathrm{U}\right.$ by thermal ionization mass spectrometry
[TIMS] and ${ }^{14} \mathrm{C}$ by accelerator mass spectrometry [AMS]) and paleobathymetric information deduced from biological communities (corals, algae, and mollusks) that live in a sufficiently narrow or specific depth range to be useful as absolute sea level indicators.

\section{Define SST variations for the region over the period 20,000-10,000 cal. y BP.}

This information is needed to gain better knowledge of regional variation of SSTs in the South Pacific, climatic variability and identification of specific phenomena such as ENSO, and global variation and relative timing of postglacial climate change in the southern and northern hemispheres.

Methods include stable isotope $\left(\delta^{18} \mathrm{O}\right)$ and trace element (Sr/Ca) analyses on high-resolution (i.e., monthly) sampling of massive coral colonies. Coupled analyses of $\delta^{18} \mathrm{O}$ and $\mathrm{Sr} / \mathrm{Ca}$ on the same sample may yield estimates of both temperature and salinity (McCulloch et al., 1996). Stable isotope $\delta^{13} \mathrm{O}$ measurements, systematically coupled with those of $\delta^{18} \mathrm{O}$ in coral skeletons, will provide information on other parameters (e.g., solar variations or metabolism processes). Geochemical methods will be coupled with measurements and analyses of the bandwidths and microstructural variations in the coral skeletons.

\section{Analyze the impact of sea level changes on reef growth and geometry.}

Assessments will be made of the impact of glacial meltwater phases (identification of reef-drowning events) and the morphological and sedimentological evolution of the foreslopes (highstand versus lowstand processes). In addition, modeling of reef building and analyses of environmental change during reef development will be undertaken.

A numerical model simulating reef building will be used to study the effect of a sea level jump on reef geometry and to qualitatively assess the effect of sea level fluctuations on the reef shape and age-depth relationships.

Expedition 310 may provide the opportunity to better constrain the last deglacial history (see Peltier, 1994; Fleming et al., 1998; Okuno and Nakada, 1999) by documenting for the first time the LGM lowstand in well-studied cores in the far field and by comparing the MWP-1A event in the Pacific and Atlantic Oceans. Furthermore, study of coral material from the late glacial to deglacial period should provide the first Sr/Ca SSTs for the LGM in the Pacific, which could then supplement Barbados sample data (Guilderson et al., 1994) and the recent study of Stage 6 corals (McCulloch et al., 1999). 


\section{Operational strategy}

Drilling offshore Barbados (Fairbanks, 1989) demonstrated that the reef sequence corresponding to the last deglaciation developed only on slopes and therefore forms discontinuous successive terraces of various lateral extent.

At Tahiti, recovery of the last deglacial reef sequence required drilling successive reef terraces that occur seaward of the living barrier reef. Studies and surveys around Tahiti have demonstrated the occurrence of successive reef terraces at various depths-100, 90, 60 , and $40-50 \mathrm{~m}$-which therefore correspond to drilling targets. Thus, at each site, we cored several boreholes along transects to attempt to recover the entire last deglacial reef sequence.

Based on the results of previous scientific drilling and bathymetric and seismic data acquired during the Sismique Haute Resolution, Bathymetrie et Dragages sur les Pentes Externes des Recifs de Tahiti (SISMITA) cruise, we drilled a transect of holes in three areas around Tahiti: offshore Faaa (proposed Site TAH-01A), Tiarei (proposed Site TAH-02A), and Maraa (proposed Site TAH-03A) (Fig. F2). Water depths at these locations ranged from 41.65 to $117.54 \mathrm{~m}$.

The exact location of the drill holes was determined during the cruise by checking the nature and morphology of the seafloor with a through-pipe underwater camera. All holes were sited within a $150 \mathrm{~m}$ radius around the proposed drilling sites approved by the Environmental Pollution and Safety Panel (EPSP), or within the midcruise EPSP-approved 200 $\mathrm{m}$ extension of the circle around proposed Site TAH02A 4 (to 350 m radius). Figures F3, F4, and F5 show the locations of the holes at Faaa, Tiarei, and Maraa, respectively.

\section{Site results}

Cores were recovered from 37 holes at 22 sites (M0005-M0026) (Table T1), with a conventionally calculated recovery of $57.47 \%$. Water depths at the sites ranged from 41.6 to $117.5 \mathrm{~m}$, and cores were recovered from 41.6 to 161.8 meters below sea level (mbsl). The initial strategy of coring along profiles has been applied, although the locations of some proposed drill sites were slightly changed because of difficulties locating and operating at those sites (see the "Operations" sections in the individual site chapters). Three transects were drilled in two regions: Tiarei (transect between inner and outer ridge sites) and Maraa (eastern and western transects). Other drilling areas include marginal sites at Tiarei and the Faaa sites. All sites were drilled within areas approved by the EPSP. Borehole geophysical wireline logging was conducted at seven sites (in ten holes).

Because of space limitations on the DP Hunter, only limited analysis of cores was conducted offshore, with the bulk of description and measurement conducted at the Onshore Science Party at the Bremen Core Repository. Table T2 shows which measurements were conducted offshore and at the Onshore Science Party.

\section{Sedimentology and biological assemblages}

Cored material shows that the fossil reef systems around Tahiti are composed of two major lithological units: a last deglacial carbonate sequence (Unit I) and an older Pleistocene sequence (Unit II). Modern sediments were often recovered above Unit I. Within Units I and II, the lithostratigraphy can be divided into subunits (e.g., Subunit IA, IB, IC, and so on) based on coral assemblages and internal structure. It is important to note that subunits of the same designation at separate sites are not correlative. Correlation of subunits between sites will not be possible until ages are obtained from postcruise research.

\section{Maraa western transect: Sites M0005-M0007}

The western transect drilled in the Maraa area (southwest Tahiti) includes Sites M0007, M0005, and M0006 (landward to oceanward) in water depths between 41.65 and $81.58 \mathrm{~m}$. Figure F6 summarizes the major lithologic units, lithology, and recovery for all holes on the Maraa western transect.

\section{Modern sediments}

Modern sediments were recovered at all sites along this transect. They consist of a few decimeter-thick beds comprising rhodoliths, skeletal sand, and gravels rich in Halimeda segments, mollusk fragments, benthic foraminifers, and nongeniculate coralline algae along with clasts of Halimeda packstone and coral clasts.

\section{Lithologic Unit I (last deglacial carbonate sequence)}

The thickness of Unit I ranges from 33.22 to $44.56 \mathrm{~m}$ at Sites M0005 and M0007, respectively.

The top of Unit I is characterized by an abundance of thin crusts of nongeniculate coralline algae and extensive bioerosion. This sequence is primarily composed of coralgal-microbialite frameworks commonly interlayered with skeletal limestone and loose skeletal sediments, including coral and algal rubble and skeletal sand.

The coralgal-microbialite frameworks that form the bulk of this unit are characterized by widespread development of microbialites, which locally represent 
the major structural and volumetric component of the reef rock. They develop within the primary cavities of the reef framework, where they generally overlie crusts of nongeniculate coralline algae. Microbialites generally comprise a suite of fabrics including two end-members represented by laminated fabrics and thrombolitic accretions; laminated fabrics generally correspond to the most abundant fabric.

The reef sequence is characterized by a general succession of distinctive coral assemblages, although many of them are intergradational, both laterally and vertically. Two successive subunits (Subunits IA and IB) displaying distinctive coral assemblages and internal structure were recognized:

- Subunit IA, up to $20 \mathrm{~m}$ thick, primarily comprises coralgal-microbialite frameworks dominated by encrusting coral colonies.

- Subunit IB, up to $25 \mathrm{~m}$ thick, comprises coralgalmicrobialite frameworks made of tabular and branching coral colonies that are usually heavily encrusted by nongeniculate coralline algae, locally associated with vermetid gastropods, overlain by very thick and massive microbialite crusts. Large primary cavities are partially filled with skeletal sand rich in Halimeda segments and coral fragments.

At Site M0007, the base of Subunit IB corresponds to poorly lithified skeletal grainstone that contains fine sand-sized volcanic grains and a $30 \mathrm{~cm}$ thick interval composed of branching coralline algae in Core 310M0007B-34R.

\section{Lithologic Unit II (older Pleistocene sequence)}

The top of Unit II was recovered at 92.85 and 86.21 mbsl at Sites M0005 and M0007, respectively. This sequence was drilled to $161.8 \mathrm{mbsl}$ in Hole M0005D.

The older Pleistocene sequence is composed of eight distinctive lithologic subunits:

- Subunit IIA is a beige to gray well-lithified limestone comprising coralgal frameworks associated with rudstone-floatstone beds.

- Subunit IIB is a well-lithified skeletal floatstonerudstone rich in rhodoliths, fragments of corals and mollusks, and Halimeda segments, associated with volcanic grains.

- Subunit IIC is a poorly sorted and ungraded unlithified volcaniclastic silt to sand including scattered skeletal grains, reworked pebbles of $\mathrm{Hal}$ imeda floatstone, and angular clasts of siltstone of the same composition.

- Subunit IID is a beige to brownish coralgal framework in which corals are thinly coated by nongen- iculate coralline algae and then heavily encrusted by microbialites with laminar and thrombolitic fabrics.

- Subunit IIE is a sandy skeletal grainstone rich in volcanic grains, large coral clasts (massive Porites), and skeletal fragments (coralline algae and corals).

- Subunit IIF is a coral and algal rudstone to floatstone comprising fragments of corals (massive, encrusting, and branching corals), coralline algae, echinoids and mollusks, rhodoliths, and lithoclasts in a coarse sandstone matrix rich in volcanic and skeletal grains.

- Subunit IIG is a coralgal framework interbedded with skeletal grainstone to packstone rich in volcanic grains.

- Subunit IIH is a skeletal grainstone to floatstone rich in fragments of corals (branching Pavona and encrusting Montipora), echinoids and coralline algae, and volcanic grains.

\section{Maraa eastern transect: Sites M0015-M0018}

The eastern transect drilled in the region of Maraa (southwest Tahiti) includes Sites M0017, M0015, M0018, and M0016 (landward to oceanward) in water depths from 56.45 to 81.8 mbsl. Figure F7 summarizes the major lithologic units, lithology, and recovery for all holes on the Maraa eastern transect.

\section{Lithologic Unit I (last deglacial sequence)}

The thickness of Unit I ranges from 35.44 in Hole M0015A at 72.15 mbsl to $39.05 \mathrm{~m}$ in Hole M0018A at $81.8 \mathrm{mbsl}$. The base of the unit has been recovered from $94.67 \mathrm{mbsl}$ at the inner sites to $122.64 \mathrm{mbsl}$ at the outer sites.

This unit is primarily composed of coralgal-microbialite frameworks commonly interlayered with loose skeletal sediments, including coral and algal rubble. Coral and algal rubble are mostly composed of accumulations of fragments of corals (mostly encrusting Acropora and Montipora and branching Pocillopora and Porites), microbialites and mollusks, Halimeda segments, and rounded lithoclasts (e.g., skeletal sandstone rich in volcanic grains). Benthic foraminifers are usually scarce. Pebbles of basalt and sandsized volcanic grains occur locally. Skeletal sand corresponds to Halimeda sand rich in fragments of corals (e.g., branching Porites), echinoids, and mollusks.

The frameworks that form the bulk of Unit I include three subunits (Subunits IA-IC) displaying distinctive coral assemblages and internal structure. Corals are usually thinly encrusted by nongeniculate coralline algae, except in Subunit IC, where the algal crusts are significantly thicker (up to $2 \mathrm{~cm}$ thick) and include vermetid gastropods. The last stage of en- 
crustation over coral colonies corresponds to thick microbialite crusts dominated by massive laminated fabrics.

- Subunit IA primarily comprises locally well lithified coralgal bindstone that forms the upper part of Unit I in all holes. In Holes M0015B and M0018A, the top of the subunit is characterized by the occurrence of a hardground and yellowreddish staining of the rock surface. Coral assemblages are dominated by encrusting (Montipora, Pavona, Porites, Leptoseris, and Leptastrea) and foliaceous coral colonies (Pachyseris). Associated corals include massive Porites and branching colonies of Porites, Pavona, and Pocillopora (including robust branching colonies). Tabular colonies of Acropora occur in the lower part of the subunit.

- Subunit IB is mostly composed of coralgal-microbialite frameworks in which coral assemblages are dominated by tabular colonies of Acropora. Associated corals include encrusting colonies of Montipora (locally dominant), Porites, Leptastrea, Montastrea, and agariciids, massive colonies of Porites and Montastrea, and branching colonies of Porites, Pocillopora, and Acropora. Robust branching colonies of Acropora and Pocillopora occur in the lower part of the subunit, where they are locally dominant.

- Subunit IC comprises coralgal-microbialite frameworks dominated by branching colonies of Porites. The coral assemblage associated with the branching colonies of Porites is well diversified and includes branching colonies of Pocillopora (including robust branching colonies) and Acropora, encrusting colonies of Porites, Montipora, Leptastrea, Millepora, Pavona, Leptoseris, and Psammocora, and tabular colonies of Acropora.

\section{Lithologic Unit II (older Pleistocene sequence)}

Unit II is primarily composed of irregular alternations of yellow and gray to beige poorly sorted skeletal limestone (grainstone to rudstone-floatstone) and coralgal frameworks with local intercalations of coral and algal rubble that display conspicuous alteration.

Subaerial diagenetic processes are indicated by recrystallization of coral skeletons and the occurrence of large solution cavities that display yellow and brown to red-brown staining. Some solution cavities are partly filled with sediments.

The grainstone, rudstone, and floatstone are rich in fragments of corals (e.g., robust branching colonies of Pocillopora, branching and massive colonies of Porites, branching colonies of Acropora, and encrusting colonies of Montipora), coralline algae, echinoids and mollusks, and Halimeda segments. Sand-sized volcanic grains are commonly associated with skeletal grains.

Coralgal frameworks comprise encrusting and branching colonies of Porites, tabular colonies of Acropora, encrusting and massive colonies of Montipora, and encrusting colonies of agariciids; massive colonies of Porites occur locally.

\section{Tiarei inner ridge: Site $\mathrm{M} 0023$}

Figure F8 summarizes the major lithologic units, lithology, and recovery for all holes on the Tiarei inner ridge.

\section{Lithologic Unit I (last deglacial sequence)}

Unit I is primarily composed of coralgal-microbialite frameworks. Manganese(?) impregnation and dark staining of corals occurs at the top of the unit. Basalt pebbles and volcanic grains are abundant toward the base of the unit.

Unit I is characterized by three successive coral assemblages (Subunits IA-IC):

- The coral assemblage in Subunit IA consists of encrusting colonies of Montipora, Pavona, Porites, and acroporids, foliaceous colonies of Pachyseris associated with branching colonies of Porites, and, to a lesser extent, robust branching colonies of Pocillopora.

- The coral assemblage in Subunit IB is composed of massive and encrusting colonies of Porites and faviids (Leptastrea) and, to a lesser extent, branching colonies of Porites that occur locally.

- The coral assemblage in Subunit IC is dominated by branching and encrusting colonies of Porites associated with encrusting colonies of Millepora, Montipora, Psammocora, and Pavona, massive colonies of Leptastrea and Porites, branching colonies of Pocillopora (including robust branching colonies), and tabular colonies of Acropora.

\section{Lithologic Unit II (older Pleistocene sequence)}

Unit II comprises brown algal bindstone, microbialites, and coralgal frameworks that exhibit evidence of late diagenetic overprints, including the alteration of coral skeletons and the occurrence of solution cavities. Basalt pebbles and lithoclasts occur throughout this unit.

Solution cavities present throughout this interval are filled with multigenerational infillings, including well-lithified pale brownish limestone and poorly lithified dark brown sandy sediments that include skeletal grains.

The coral assemblage includes massive and encrusting colonies of faviids, robust branching and tabular 
colonies of Acropora, encrusting colonies of agariciids, and branching colonies of Porites.

\section{Tiarei outer ridge: Sites M0009, M0021, and M0024-M0026}

Figure F9 summarizes the major lithologic units, lithology, and recovery for all holes on the Tiarei outer ridge.

\section{Lithologic Unit I (last deglacial sequence)}

On the outer ridge of Tiarei, Unit I was recovered from 81.7 to 122.12 mbsl. The thickest continuous sequence was recovered from Holes M0021A and M0021B, in which its thickness reaches $29.98 \mathrm{~m}$.

Unit I mostly comprises coralgal-microbialite frameworks that are locally interlayered with volcaniclastic sediments, including coarse sand displaying skeletal elements (foraminifers, Halimeda segments, fragments of mollusks, bryozoans, corals, and especially branching colonies of Porites), rubble and sand composed mostly of coral fragments (mostly branching colonies and, to a lesser extent, tabular colonies), and skeletal packstone to floatstone rich in Halimeda segments as well as coral and mollusk fragments.

The top of Unit I is characterized by the widespread development of micritic microbial crusts that display laminar and knobby morphologies. Extensive bioerosion, dark to brown staining within the uppermost $2-3 \mathrm{~m}$ of the unit, and hardgrounds are features that were locally observed.

Coralgal-microbialite frameworks are characterized by distinctive internal structure and coral assemblages. Five lithologic and coral assemblages (Subunits IA-IE) display a general consistent trend:

- Subunit IA, the uppermost assemblage, is dominated by encrusting colonies of Montipora, Montastrea, Leptastrea, Pavona, and Porites and encrusting foliaceous colonies of Pachyseris and Leptoseris.

- Subunit IB is dominated by branching and encrusting colonies of Porites and Montipora; associated corals include encrusting and branching colonies of Pavona and, to a lesser extent, branching colonies of Pocillopora, tabular colonies of Acropora, and encrusting colonies of agariciids.

- Subunit IC is dominated by massive colonies of Porites; some colonies display traces of bioerosion.

- Subunit ID is dominated by robust branching colonies of Pocillopora and encrusting colonies of faviids and encrusting and branching colonies of Montipora.

- Subunit IE, the bottommost assemblage, is composed of encrusting and massive colonies of faviids (Favia and Leptastrea) locally associated with encrusting colonies of Montipora. Associated coral rubble comprises mostly fragments of branching colonies of Porites, Acropora, and Pocillopora.

The thickness and morphology of the microbial crusts are closely related to the morphology and size of the cavities in which they developed. In bindstone formed by encrusting coral assemblages, microbialites are dominated by thrombolitic fabrics, whereas in frameworks made of branching and massive coral colonies, they are characterized by the development of compound crusts, up to $15 \mathrm{~cm}$ thick, formed by a succession of laminated and thrombolitic fabrics, where thrombolites usually represent the last stage of encrustation. Thrombolites consist of closely spaced and vertically and laterally intergradational micritic masses that range from narrow millimeter-sized upward-radiating shrubs to broader dendritic clusters as high as $1 \mathrm{~cm}$. Multiple generations may be closely packed and merge into micritic crusts as thick as several centimeters.

\section{Lithologic Unit II (older Pleistocene sequence)}

The contact between Units I and II is characterized by an irregular unconformity typified by an abundance of large solution cavities partly filled with unconsolidated skeletal and volcanic sand, including coralline algal branches and Halimeda segments and coral gravels (Pocillopora branches and fragments of Montipora colonies). Some cavities are partly filled with skeletal and volcanic sands and gravels and stalagmite crusts. Several unconformities occur in the upper part of Unit II.

Unit II comprises four lithologic subunits (Subunits IIA-IID) that are locally interlayered:

- Subunit IIA is composed of well-lithified gray to brown coralgal frameworks with coral assemblages dominated by encrusting colonies of Leptastrea, Pachyseris, Montipora, and Psammocora, locally associated with robust branching colonies of Acropora and Pocillopora, tabular colonies of Acropora, and massive colonies of Porites associated with coral rudstone-floatstone and skeletal limestone.

- Subunit IIB comprises coral clasts, limestone clasts, basalt pebbles, and reworked coral colonies (Porites and robust branching Acropora).

- Subunit IIC is a sandy packstone/grainstone with coral clasts (branching colonies of Acropora and Pocillopora) overlying a coral boundstone characterized by abundant, massive colonies of Porites and encrusting colonies of unidentified corals associated with clasts of robust branching colonies of Acropora.

- Subunit IID is a massive weakly consolidated and cemented dark gray to brownish volcaniclastic 
siltstone to sandstone that includes pieces of corals (branching colonies of Pocillopora and encrusting colonies of Montipora) and coralline algal crusts and skeletal fragments (small-sized mollusk shells and Halimeda segments) interlayered with sandy limestone and granule- to pebble-sized pieces of aphanitic dense basalt.

\section{Tiarei marginal sites: Sites M0008, M0010- M0014, and M0022}

\section{Holes dominated by volcaniclastic sediments}

Hole M0008A exhibits a $38.7 \mathrm{~m}$ thick sequence (64.15-102.85 mbsl) composed of two lithological units:

- Unit I is a black uncemented to weakly consolidated volcaniclastic sand, silt, and clay interlayered with beds comprising basalt pebbles, cobbles, and boulders.

- Unit II is an orange, dark brown, to reddish brown volcaniclastic siltstone to sandstone interlayered with volcaniclastic sand and silt, volcaniclastic cobble, and rubble.

The boundary between the two units is marked by a change from silt/sand to siltstone/sandstone and a color change from gray to orange-brown. In Hole M0021B, a similar color change coincides with the Unit II/I boundary. Figure F10 summarizes the major lithologic units, lithology, and recovery for all holes at Tiarei marginal sites.

\section{Holes composed of volcaniclastic sediments and carbonates}

Lithologic Unit I (last deglacial sequence)

In holes located close to the outer ridge (Holes M0010A-M0014A), Unit I comprises three successive subunits (Subunits IA-IC) that were recovered from 78.85 to 117.98 mbsl:

- Subunit IA was recovered only at Site M0012 from 78.85 to 107.18 mbsl. It is mostly composed of loose sediments (coral rubble and skeletal silt and sand) locally interlayered with volcaniclastic sand rich in skeletal grains.

- Subunit IB, recovered in an interval ranging generally from 90 to $100-105$ mbsl, is dominated by volcaniclastic sediments that are locally interlayered with beds comprising carbonate elements and coral colonies.

- Subunit IC, ranging from 100 to $115 \mathrm{mbsl}$, is primarily comprised of coralgal-microbialite frameworks interlayered with beds composed of (1) coral rubble, fragments of coralline algal crusts, and microbialites mixed with sand- to peb- ble-sized volcanic elements, (2) skeletal sand rich in Halimeda segments, foraminifers, and fragments of mollusks and coralline algae mixed with volcanic grains, and (3) volcaniclastic and skeletal sand and silt. The frameworks comprise two distinctive coral assemblages:

- The first assemblage is dominated by encrusting colonies of Montipora, agariciids, and faviids and thin branching colonies of Porites.

- The second assemblage consists of massive colonies of Porites and faviids locally associated with branching colonies of Pocillopora and Montipora.

Lithologic Unit II (older Pleistocene sequence)

The boundary between Units I and II is sharp. Unit II is composed mainly of well-lithified gray to light brown coralgal boundstone, coral rudstone, and skeletal sandy limestone, interlayered locally with horizons of gravels and rubble made of that material. The coral assemblage is dominated by foliaceous colonies of Pachyseris, tabular and branching colonies of Acropora, robust branching colonies of Pocillopora, encrusting and branching colonies of Montipora, and branching and massive colonies of Porites. Microbialites are abundant and include laminated and thrombolitic fabrics. The matrix of the limestone is rich in Halimeda segments; volcanic grains are locally abundant. Subaerial diagenetic processes are indicated by the alteration of coral skeletons and the occurrence of large solution cavities that are filled with volcaniclastic and skeletal sandstone and by gravels and rubble including branches of Pocillopora and basalt pebbles at the top of the unit.

\section{Faaa: Sites M0019 and M0020}

Sites M0019 and M0020 were drilled at 58.5 and 83.3 mbsl, respectively. The location of the boundary between Units I and II in the two holes was defined on the basis of lithologic and diagenetic features; it occurs at 81.94 mbsl in Hole M0019A and at 92.05 mbsl in Hole M0020A. Figure F11 summarizes the major lithologic units, lithology, and recovery for all holes at Faaa sites.

\section{Lithologic Unit I (last deglacial sequence)}

Unit I at Sites M0019 and M0020 is 23.19 and $8.75 \mathrm{~m}$ thick, respectively, and displays a very similar composition in the two holes. It primarily comprises loose coralgal-microbialite frameworks (bindstone) interlayered with beds of coral rubble. These beds are composed of reworked and rounded fragments of corals (branching colonies of agariciids and Porites), coralline algal crusts, and microbialites that are extensively bored and stained. 
The coralgal-microbialite frameworks are dominated by encrusting colonies of Montipora, agariciids (Pavona?), Acropora, Psammocora, and Echinophyllia associated locally with massive colonies of Porites, Montastrea, Cyphastrea, and Leptastrea, encrusting colonies of Leptoseris, and fragments of robust branching colonies of Pocillopora, tabular colonies of Acropora, and branching colonies of Porites. Microbialites consist of dark gray laminated dense and thrombolitic fabrics; the latter are usually dominant. Large cavities, partly to fully filled with skeletal sand rich in Halimeda segments (Halimeda packstone), commonly occur. Reddish brown to black staining on the surface of reef rocks is conspicuous in some cores.

\section{Lithologic Unit II (older Pleistocene sequence)}

Unit II at Sites M0019 and M0020 is 43 and $33 \mathrm{~m}$ thick, respectively, and displays a distinctive composition in the two holes. The coralgal-microbialite frameworks in the bulk of this unit are characterized by the widespread development of microbialites.

In Hole M0019A, Unit II includes three subunits (Subunits IIA-IIC) characterized by their distinctive lithology and composition and separated by unconformities at 106.2 and $121.12 \mathrm{mbsl}$, respectively:

- Subunit IIA is $24 \mathrm{~m}$ thick and comprises irregular alternations of beige coralgal and skeletal limestone bearing in situ coral colonies and beds of coral rubble. The coral assemblages forming the coralgal frameworks consist of massive colonies of Porites, branching and encrusting colonies of Porites, and, to a lesser extent, encrusting colonies of agariciids, Montipora, and Millepora, massive colonies of Leptastrea and Montastrea, and tabular colonies of Acropora. Fragments of branching colonies of Pocillopora occasionally occur. Skeletal limestone consists of a well-lithified rudstone that includes subrounded coral fragments (branching and massive colonies of Porites, robust branching colonies of Pocillopora, and tabular colonies of Acropora) often encrusted by coralline algae and locally surrounded by cement fringes. Other skeletal grains include Halimeda segments and fragments of echinoids, coralline algae, and mollusks.

- Subunit IIB is $15 \mathrm{~m}$ thick and comprises yellowish brown skeletal floatstone to grainstone, including rhodoliths, foraminifers, and fragments of corals (branching and encrusting colonies of Porites, robust branching colonies of Pocillopora, and tabular colonies of Acropora) and coralline algae, echinoids, and mollusks; sand-sized volcanic grains occur in the lower part of the subunit and their abundance increases downhole.
- Subunit IIC is $11 \mathrm{~m}$ thick and comprises irregular alternations of coralgal frameworks, skeletal limestone, and rubble beds. Coralgal frameworks are dominated by tabular colonies of Acropora, massive colonies of Porites (e.g., Cores 310-M0019A27R and 28R), encrusting colonies of Porites and Montipora, and robust branching colonies of Acropora. Skeletal limestone consists of a very poorly sorted rudstone rich in large coral fragments (tabular Acropora, robust branching Pocillopora, branching Porites, and encrusting agariciids), rhodoliths, Halimeda segments, and fragments of coralline algal crusts, mollusks, and echinoids.

In Hole M0020A, Unit II is primarily composed of coralgal frameworks locally interlayered with skeletal limestone and rubble beds. These frameworks are dominated by branching and encrusting Porites, locally associated with encrusting colonies of Montipora and Pavona, and robust branching colonies of Pocillopora. The interlayered skeletal limestone consists of Halimeda wackestone and poorly sorted coral rudstone, including fragments of branching and encrusting colonies of Porites, robust branching colonies of Pocillopora and Acropora, and encrusting colonies of Montipora. Other skeletal grains include Halimeda segments and fragments of mollusks and echinoids; volcanic silt to sand grains are locally abundant.

\section{Physical properties}

Coral reefs present special challenges for geological and geophysical studies. Reef growth is highly variable over small spatial scales, and widely spaced cores may not accurately resolve patterns of coral accumulation (Jordan and Wilson, 1998). Generally, carbonate systems are difficult to image using reflection seismic technologies because of their spatially highly variable acoustic properties, which are a result of their intrinsic pore systems during evolution and diagenetic overprint. At the same time, carbonate reef deposits hold more than half of the world's hydrocarbon accumulations and represent major water aquifers in many places around the globe. Expedition 310 presents a unique opportunity to petrophysically quantify modern reef development before pronounced overprinting by diagenetic processes and to advance the understanding of such acoustically complex coralgal reef systems.

Three sequences were identified during Expedition 310 , each with specific physical properties. As the physical properties in carbonates are highly variable, no particular values of individual parameters are given in the following section; instead, they are included in individual site chapters. 
The last deglacial sequence comprises coralgal frameworks heavily encrusted by microbialites locally interlayered with coarse skeletal sand and gravels rich in coral and algal fragments. Large primary cavities in coralgal frameworks are open or partially filled with skeletal sand and gravels, including coral and coralline algal fragments, and with Halimeda segments. Microbialites are very abundant and represent the major and structural and volumetric component of the reef rock. The open framework and centimeter- to decimeter-size pores result in a highly variable physical system. Physical properties change on a centimeter scale and may range from low porosity, high density and velocity to $100 \%$ open pore space (see Fig. F67 in the "Maraa eastern transect" chapter). In situ corals, microbialites, and skeletal sand all have a distinct petrophysical signature (acoustic velocity, porosity, grain density, and color reflectance $L^{*}$ values) but cannot be correlated easily from hole to hole.

The last deglacial sequences at Maraa and Tiarei display a difference in level of volcaniclastic component, with the reef at Tiarei containing a greater volumetric component, which can be observed on digital image scans and quantified by both diffuse color reflectance spectrophotometry and magnetic susceptibility logs. Minor amounts of noncarbonate material, clay, and/or quartz silt/sand can dramatically change acoustic velocities (Stafleu et al., 1994; Kenter et al., 1997; Anselmetti and Eberli, 2001). Magnetic susceptibility values are lower in the last deglacial sequence at Maraa than in that of Tiarei (cf. Fig. F69 in the "Maraa western transect" chapter and Fig. F11 in the "Tiarei inner ridge" chapter). Also, clear subdivision of intervals with different inputs of magnetic minerals is possible within individual sites. For instance, in Hole M0025B (see Fig. F67 in the "Tiarei outer ridge" chapter), the interval from 0 to 8 meters below seafloor (mbsf) displays a different magnetic susceptibility response than the one from 8 mbsf downward. It is inferred that the course of the Tiarei River changed through time and delivered different amounts of volcaniclastic material to the reef.

The contact between the last deglacial sequence and the older Pleistocene carbonate sequence is characterized by an irregular unconformity; abundant solution cavities at the top of the underlying limestone are partly filled with unconsolidated skeletal and volcanic sand, including coralline algal branches, coral gravels, and Halimeda segments. The change in physical properties at this contact is sharp and abrupt. Density, velocity, and magnetic susceptibility increase, whereas porosity decreases (e.g., Hole M0007A, Fig. F69 in the "Maraa western transect" chapter, and Hole M0015A, Fig. F66 in the "Maraa eastern transect" chapter).

The older Pleistocene sequence is composed of (1) well-lithified skeletal packstone to floatstone/rudstone, (2) well-lithified coralgal frameworks, and (3) beds comprising rubble and gravels primarily composed of coral clasts, limestone clasts, basalt pebbles, and reworked coral colonies. All three units are generally well lithified and have undergone several phases of diagenetic alteration. This results in tight, low porosity, high velocity limestones with a much smaller range in variation of physical properties than observed for the younger sequences. Volcanic pebbles and sands are locally interlayered and/or mixed with carbonate and are associated with an increase in magnetic susceptibility values (e.g., Hole M0005D, Fig. F68 in the "Maraa western transect" chapter).

The third sequence, occurring in Hole M0008A, consists of volcaniclastic sediments and rocks: clays, unto semilithified sandstone, basalt gravels, pebbles, and cobbles. Sandstone is commonly moderately lithified and has high densities and relatively low velocities. Basalts are high in density and velocity. Magnetic susceptiblity in this unit is generally high (e.g., Hole M008A, Fig. F9 in the "Tiarei marginal sites" chapter).

Existing studies show that the primary factors controlling acoustic properties in carbonates are the amount and type of porosity, diagenetic properties, and mineralogy. Carbonates do not have large compositional variations that are, as is the case in other sedimentary rocks, responsible for velocity contrasts (e.g., Braaksma et al., 2003). Pure carbonates are characterized by a lack of any clay or siliciclastic content but are mostly produced and deposited on top of or on the slope of isolated or detached carbonate platforms, which have no hinterland as a source of terrigenous material (Wilson, 1975; Eberli, 1991). They consist of $>95 \%$ of the carbonate minerals calcite (low and high $\mathrm{Mg}$ ), dolomite, and aragonite. These minerals have very similar physical properties, which excludes compositional variation as a major reason for the large variability in velocity of carbonates. In Tahiti, however, reefs are contaminated with volcaniclastic input from the island. These inputs are more abundant at Tiarei than at Maraa but cannot be neglected for having influence on acoustic properties. Anselmetti and Eberli (1993) show that departures from general trends of correlation can be as high as $2500 \mathrm{~m} / \mathrm{s}$, and attribute this to the occurrence of different pore types that form both as a result of depositional processes and as specific diagenetic stages. Most studies show at the same time the poorly defined porosity-velocity trend and large de- 
viations from classic and widely used velocity transforms as the Wyllie "time-average" (WTA; Wyllie et al., 1956, 1958) equation and the Raymer-HuntGardner (RHD; Raymer et al., 1980) equation. In addition, theories that describe sonic wave propagation in porous media (Gassmann, 1951; Biot, 1956a, 1956b) are hard to apply in the complex system of pure carbonates because they form a variety of unique diagenetic rock fabrics with specific elastic properties. These complexities make the relationships between petrophysical properties and acoustic properties of carbonates rather complicated.

A cross plot of velocity versus porosity for all sites shows a negative inverse relationship (Fig. F12) between acoustic velocity $\left(V_{\mathrm{p}}\right)$ and porosity. Instead of showing individual data points for bulky MSCL data $(15,191$ data points), data density was contoured. MSCL data were acquired cross core (over $\sim 6.5 \mathrm{~cm}$ ), whereas core plugs were never longer than $3 \mathrm{~cm}$ and could only be drilled in appropriate core sections. The scale-dependency of petrophysical measurements, along with the difference in selective sampling of core as opposed to bulk MSCL measurements is illustrated in Figure F12; for a given porosity value discrete measurements have higher $V_{\mathrm{P}}$ values than MSCL measurements. The WTA equation gives the best fit-the smallest error-with the MSCL data, whereas the RHD equation shows the best fit for the discrete samples. The deviation between both velocity transforms and the Tahiti data points, however, is still high. On the high end of the range in velocity for a given porosity, these differences can be interpreted as the added effect of pore characteristics like pore shape and connectivity and mineralogical and textural properties of the coralgalmicrobial frameworks. Differences on the low end of the range in velocity for a given porosity may very well originate from the lack of burial compaction and/or pronounced diagenesis.

\section{Downhole logging}

Downhole geophysical logs provide continuous information on physical, chemical, textural, and structural properties of geological formations penetrated by a borehole. In intervals of low or disturbed core recovery, downhole geophysical logs provide the only way to characterize the borehole section. This is especially true when recovery is poor and when comparable measurements or observations are obtained from core, as downhole geophysical logs allows precise depth positioning of core pieces by visual (borehole images) or petrophysical correlation.

The set of borehole geophysical instruments was constrained by the scientific objectives and the geological setting of the expedition. A suite of downhole geophysical methods was chosen to obtain high-resolution images of the borehole wall, to characterize the fluid nature in the borehole, to measure borehole size, and to measure or derive petrophysical or geochemical properties of the formation such as porosity, electrical resistivity, acoustic velocities, and natural gamma radioactivity. Because of environmental constraints, no nuclear tools were deployed during Expedition 310.

A total of 10 boreholes were prepared for downhole geophysical measurements. All measurements were performed under open borehole conditions (no casing) with the exception of a few of spectral gamma ray logs (see the "Downhole logging" sections in the individual site chapters). After completion of coring, the drill string was pulled and the coring bit was changed for an open shoe casing to provide borehole stability in unstable sections and a smooth exit and entry of logging tools. In addition, a wiper trip was performed with seawater (no drilling mud was used). Borehole conditions were extremely hostile, and very often the boreholes had to be logged in intervals where the HQ drill string was used as a temporary casing. To be able to record ultra high resolution geophysical downhole logging data, acquisition was done in the rooster box, which, in the piggyback drilling system used, is heave compensated. Because of difficult borehole conditions and time constraints, it was not possible to log all tools in every borehole.

The measured geophysical parameters, including optical and acoustic borehole wall images, provided a source of continuous information of the drilled sequences. During Expedition 310, the televiewer tools (OBI40 and ABI40) had particular value. By unrolling the images of the borehole wall $\left(360^{\circ}\right)$ into a two-dimensional (2-D) view, a section of $\sim 31 \mathrm{~cm}$ is obtained, compared to a $6.54 \mathrm{~cm}$ cross section of a split core obtained by HQ-diameter drill bit. These images allow not only the precise positioning of pieces of core in areas of low recovery but also permit direct determination of coral growth forms and verification if coral colonies are in life position. In addition, the images provide a superb macro- and mesoscale characterization of the pore system in reef rocks. Centimeter- to decimeter-size pores and cavities are common in reef frameworks. Core recovery was calculated at $\sim 57 \%$, but image logs show that by including the open pore space, true recovery was actually much higher, potentially $>90 \%$. This contributes to the conclusion that coring was highly successful in carbonate reef environments during Expedition 310.

Wireline logging operations at Maraa sites produced nearly complete downhole coverage of the last deglacial sequence from 41.65 to $102 \mathrm{mbsl}$. Tools have 
different data coverage in various holes (see the "Downhole logging" sections in the individual site chapters). In Figure F75 in the "Maraa eastern transect" chapter, borehole televiewer images, natural radioactivity logs (total counts), and electrical resistivity logs are plotted in meters below sea level. In each of the logged boreholes, the boundary between the last deglacial and older Pleistocene sequences is indicated. The depth below present-day sea level of the top of the older Pleistocene sequence is highly variable, indicating a rugged morphology prior to the development of the last deglacial sequence. Resistivity does not show any direct signal, but spectral gamma ray logs indicate a significant increase of counts in the older Pleistocene sequence (Holes M0005D and M0007A). Caliper, borehole fluid characterization, and acoustic tools all contain particular information on parameters for specific intervals and lithologies.

Wireline logging operations at Tiarei sites produced nearly complete downhole coverage of the last deglacial sequence from 72 to $122 \mathrm{mbsl}$. Tools have different data coverage in various holes (see the "Downhole logging" sections in the individual site chapters). It was not possible to image the boundary between Units I and II, except in Holes M0021B and M0023B.

In Figure F79 in the "Tiarei outer ridge" chapter, borehole images and natural radioactivity logs (total counts) are plotted in meters below sea level. In each of the logged boreholes, the boundary between the last deglacial and older Pleistocene sequences is indicated. The basal part of Unit I, directly overlying this boundary, is often semiconsolidated and poorly recovered and shows elevated natural gamma radioactivity values in proximal locations (e.g., Hole M0023B). Distal locations do not show this higher gamma ray signature, with the exception of Hole M0021B.

In Figure F80 in the "Tiarei outer ridge" chapter, borehole images and formation electrical resistivity (resistivity) are plotted in meters below sea level. The general resistivity pattern and absolute values in the last deglacial sequence along this transect are comparable across the holes. In each hole, the basal interval has the lowest resistivity values and then values increase gradually to a maximum value, after which a sharp negative excursion to lower values can be observed. However, the interval of increasing resistivity values is interrupted once by a subtle but clear decrease in the middle part of the last deglacial sequence. The absolute values of this decrease are higher at distal sites than at proximal ones. Caliper, borehole fluid characterization, and acoustic tools all contain particular information on parameters for specific intervals and lithologies.

As in the Maraa transect, the depth of the top of the older Pleistocene sequence below modern day sea level in the Tiarei transect is highly variable and indicates a very uneven paleotopography before the last deglaciation.

No logging operations were carried out at Faaa sites.

Despite operational difficulties associated with logging recent coralgal reef systems, geophysical downhole data are of high quality. The continuous information quantifies a variety of physical properties of the Tahiti fossil reef systems. The results, and especially the imaging of the borehole wall using optical and acoustic geophysical methods, complement the sedimentological descriptions and allow an unambiguous correlation of cores (through coral assemblages and sedimentological features), core logs (MSCL), downhole logs, and drilling parameters.

\section{Microbiology}

Samples from Tahiti drill cores were analyzed for evidence of microbial activity, possibly related to the formation of microbialites. To date, onboard measurements have shown a certain degree of microbial activity directly attached to mineral surfaces. According to the activity measurements along the drill cores, the uppermost part, $0-4$ mbsf of the Tahiti reef environment, is the most active zone. This is a common trend in reef environments due the closeness to the photic zone inhabited by primary producing eukaryotes, such as algae. Pure microbiological activity was only observed in reef cavities where prokaryotic biofilms have appropriate conditions to develop (Figs. F13, F14).

Preliminary results show that biofilms are diverse in structure and color. Figure F13 shows an association between a brown iron/manganese crust and a biofilm, whereas Figure F14 shows an unusual blue biofilm, which exhibited the highest degree of adenosine triphosphate (ATP) activity (20,600 RLU). In this sample, it was possible to define spherical assemblages of carbonate minerals embedded in microbial exopolymeric substances (EPS). Figure F15 shows 4,6-diamindino-2-phenylindole (DAPI)-stained cells in high densities in this biofilm in conjunction with mineral precipitation, which is most probably carbonate.

Biofilms appear to have high diversity in macroscale observations, and they are equally diverse and heterogeneous in microscale resolution, as observed by scanning electron microscopy (SEM). Carbonate minerals appear in close relation with claylike minerals (Fig. F16; Hole M0007C), carbonate microfossils 
(Fig. F17; Hole M0015B), and oxidized and reduced Fe minerals such as pyrite (Fig. F18; Hole M0023A). The metabolic processes responsible for the precipitation of this variety of minerals could not be defined as yet because of the complex and diverse conditions of the microenvironments where these biofilms were found.

Some evidence for heterotrophic metabolic activities is shown by exoenzyme measurements, which vary in the different biofilm samples. For instance, samples from Holes M0020A (4.51 mbsf) and M0009D (3.64 mbsf) showed high phosphotase activity, suggesting the occurrence of a heterotrophic community that preferentially degrades organic-bound phosphate compounds such as phospholipids or nucleic acids. In contrast, Hole M0007B (6.28 mbsf) showed only glucosidase and aminopeptidase activity, which indicates degradation and metabolization of polysaccharides and proteins.

Isolation of microorganisms from biofilm samples was performed on agar plates using a medium that is selective for heterotrophic bacteria. After 2 weeks incubation time, 10 different heterotrophic colonies could be isolated (see Fig. F5 in the "Microbiology" chapter). From anaerobic experiments, only one isolation was successful. Distinct groups of microorganisms are associated in the biofilm that could range from aerobic to anaerobic metabolism. SEM investigation of microbialite samples shows evidence that anaerobic conditions must have prevailed at times. The occurrence of pyrite well distributed in the sediment supports the occurrence of a certain degree of anoxia in the environment. Some sediment samples also show a close spatial association between the mineral phase and microbes (e.g., Figs. F17, F19).

As a biogeographical summary of microbial activity in the Tahiti reef, northwestern Faaa Hole M0020A and southwestern Maraa Holes M0005C, M0007B, M0007C, M0015B, and M0018A were more active than the northeastern Tiarei sites, where usually no living biofilm could be detected in cavities along the core.

\section{Geochemistry}

\section{Site M0008 interstitial water data}

Hole M0008A was drilled more proximal to the island of Tahiti than any other sites and recovered volcaniclastic sediments. This made Hole M0008A unique and offered opportunities to sample and analyze pore waters. In all the IW profiles, a barrier to diffusion is evident at $\sim 18 \mathrm{mbsf}$, which corresponds to the position of a large basalt boulder recovered in Section 310-M0008A-8R-1. The lack of a chilled margin at the top and bottom of this basalt suggests it is not a continuous layer of basalt providing an impervious layer. However, the seismic profile used for site selection indicates a strong continuous reflector at approximately the same depth (see Fig. F5 in the "Site surveys related to IODP Expedition 310" chapter), suggesting the basalt may represent a continuous layer. Ultimately, with no recovery of Core 310M0008A-7R above the basalt, the nature of the diffusion barrier will remain uncertain.

\section{pH, alkalinity, ammonia, chloride, and sulfate}

Above 18 mbsf, the $\mathrm{pH}$ of IW samples is similar to ambient seawater, but below the diffusion barrier, $\mathrm{pH}$ decreases sharply with depth until pore waters are slightly acidic (Fig. F20A). The IW alkalinity profile essentially traces that of $\mathrm{pH}$ (Fig. F20B). This increase in free $\mathrm{H}^{+}$ions results in an undersaturation of aragonite and calcite as calculated using the PHREEQC computer program (Parkhurst and Appelo, 1999) and shown in Figure F20A. Just below 18 mbsf, significant amounts of ammonia are detected (Fig. F20C), indicating microbial activity. The ammonia appears to diffuse downward from this source just below the diffusion barrier. Chloride in pore waters is essentially similar to seawater with a slight depletion at the bottom of the section, precluding the influence of significant amounts of freshwater in these sediments. Sulfate concentrations do not significantly deviate from seawater values at any depth.

\section{$\mathrm{Mg}, \mathrm{K}, \mathrm{Ca}$, and $\mathrm{Sr}$}

There is no significant deviation of IW Mg concentrations from that of seawater, whereas $\mathrm{K}$ becomes depleted with depth below the diffusion barrier at $\sim 18$ mbsf (Fig. F20D). Both Ca and Sr concentrations become highly elevated with depth below the diffusion barrier (Fig. F20E, F20F), indicating dissolution of carbonate debris and/or weathering of the silicate material. The calculated undersaturation of calcite and aragonite in these pore waters suggests that carbonate dissolution must be contributing to these enrichments.

\section{$\mathrm{Li}, \mathrm{P}, \mathrm{Mn}, \mathrm{Fe}$, and $\mathrm{Ba}$}

$\mathrm{Li}$ is depleted with respect to seawater value $(\sim 174$ $\mu \mathrm{g} / \mathrm{L})$ at all depths in Hole M0008A, suggesting Li uptake by clays in the siliclastic sediments (e.g., Zhang et al., 1998). P displays little variability with depth. Enrichment of the pore waters in $\mathrm{Mn}$ is observed in all samples from Hole M0008A, but there is an important source at $\sim 20$ mbsf below the diffusion barrier (Fig. F20G). Fe is greatly elevated in the IW samples from above the diffusion barrier at $\sim 18 \mathrm{mbsf}$ but was below detection in the samples from below the diffusion barrier (Fig. F20H). This pattern is un- 
expected because conventional wisdom suggests that Mn oxide reduction occurs above the zone of Fe oxide reduction in marine sediments (e.g., Berner, 1980). One possible explanation for this pattern is that most $\mathrm{Fe}$ has already been lost from the older sediments below the diffusion barrier. However, iron oxide-rich sediments containing small root fragments indicative of a laterite soil were recovered in this interval of Fe-free pore waters. It is interesting that Mn can be mobile in these sediments below the diffusion barrier and $\mathrm{Fe}$ is not. $\mathrm{Ba}$ is highly enriched in the pore waters below the diffusion barrier at $\sim 18$ mbsf, leading to a calculated barite oversaturation.

\section{X-ray fluorescence}

Five samples of volcanic sand/silt units and nine individual basalt samples were selected for bulk rock analysis by energy dispersive polarized X-ray fluorescence (EDP-XRF) analysis. All samples analyzed by this technique were taken from Hole M0008A. Analytical results are shown in Table T3. The low $\mathrm{SiO}_{2}$ but fairly high $\mathrm{K}_{2} \mathrm{O}, \mathrm{P}_{2} \mathrm{O}_{5}$, and $\mathrm{TiO}_{2}$ contents $\left(\mathrm{Na}_{2} \mathrm{O}\right.$ was not analyzed) suggest that the volcanic rock samples belong to the alkalic basalt family (i.e., alkalic basalt, basanite, tephrite, and nephelinite). The two texturally similar samples that apparently come from a single boulder show many compositional similarities, but they also have differences, especially with respect to $\mathrm{MgO}$ contents. The differences may be due to flow differentiation, which is known to create compositional variation within a lava flow, or to instrumental error. Two samples are fairly primitive ( $>14.0 \mathrm{wt} \% \mathrm{MgO}$ and $>350 \mathrm{ppm} \mathrm{Ni}$ ), but one is highly olivine-pyroxene phyric, and thus its composition may have been changed by crystal accumulation of the olivine and pyroxene. Despite their small number, the rock samples apparently show downhole compositional variation (see Fig. F15 in the "Tiarei marginal sites" chapter). Samples from the upper part of the hole have slightly higher incompatible element contents (e.g., $\mathrm{K}$ and $\mathrm{Rb}$ ) but lower $\mathrm{SiO}_{2}$ than those from the lower part of the hole, indicating that the shallow basalt samples are compositionally more alkalic than the deeper samples.

Volcaniclastic sand/silt samples are compositionally different from whole rock basalt samples in that they have lower $\mathrm{SiO}_{2}$ contents, which translates to lower total weight percent of all major oxides, obviously due to higher volatile contents, mainly seawater, as evidenced by their high $\mathrm{Cl}$ contents. Sulfur is also high in sand/silt samples, particularly in the upper samples. The only rock sample that is high in both $\mathrm{S}$ and $\mathrm{Cl}$ is a scoriaceous pebble that probably contains abundant pore water. Nevertheless, the upper sand/ silt samples show many compositional similarities to the basalts, but the lower samples do not. The upper and lower sand/silt samples show apparent compositional differences (see Fig. F19 in the "Tiarei marginal sites" chapter). Downhole compositional variations are observed in pore water chemistry, and thus the compositional differences between the upper and lower sand/silt samples are probably real. Unlike the downhole compositional variation of the basalts, the sand/silt compositional differences are most probably due to differences in depositional settings between the upper and lower volcanic sand/silt intervals.

Both parts of the island of Tahiti, Tahiti-Nui and Tahiti-Iti, are composed predominantly of lava flows of moderately alkalic to strongly alkalic basalts; plutonic rocks are subordinate in amount and only exposed near their eroded centers (e.g., McBirney and Aoki, 1968; Cheng et al., 1993; Duncan et al., 1994). Differentiated rocks occur in subordinate amounts and were erupted mostly in the waning stages of volcanic activity. Thus, the lithologic composition of the volcaniclastic sediments drilled during Expedition 310 , particularly the preponderance of lithic basalt clasts, is a direct reflection of the geology of the island. Compositionally, the rock samples and the two upper sand/silt intervals plot with the rest of the igneous samples from Tahiti (see Fig. F20 in the "Tiarei marginal sites" chapter). The two primitive basalts plot with the relatively fewer high-MgO basalts from Tahiti, whereas the other basalt samples plot with the more abundant, lower MgO basalts. Many of the lower $\mathrm{MgO}$ basalts in Tahiti can be modeled as crystal fractionation daughters of the higher $\mathrm{MgO}$ parents (e.g., Cheng et al., 1993; Duncan et al., 1994). The two upper volcaniclastic sand/silt samples plot between the two basalt groups, either because their lithic basalt components are less fractionated than the lower $\mathrm{MgO}$ basalts or because they are similar to the latter but contain additional pyroxene mineral components. The three lower sand/silt samples generally plot outside the Tahiti lava field, suggesting that their compositions have been modified or altered.

\section{Preliminary scientific assessment}

During the Expedition 310 Onshore Science Party, emphasis was placed on visual description, measurement of physical properties, and sampling of the cores. Thus, this "Expedition Reports" section of IODP Proceedings volume 310 contains a descriptive framework for subsequent postcruise research.

The primary objectives of Expedition 310 require the use of specialized geochemical techniques, paleomagnetic analyses, and detailed investigation of lith- 
ological and biological assemblages. These types of analyses were not conducted during the Onshore Science Party but will be conducted over the coming months at the institutions of the Expedition Scientists as part of their postcruise research.

Fulfillment of the Expedition 310 scientific objectives is as follows:

\section{Establish the course of postglacial sea level rise at Tahiti (i.e., define the exact shape of the deglaciation curve for the period 20,000- 10,000 cal. y BP).}

During the offshore phase, cores were recovered from the last deglacial reef sequence from 40 to 121 $\mathrm{m}$ below current sea level. Therefore, most, if not all, of the last deglacial sequence was recovered. During the Onshore Science Party, high-quality coral samples were taken for dating and sea level change investigations, the results of which are expected to fulfill the first objective.

\section{Define SST variations for the region over the period 20,000-10,000 cal. y BP.}

During the offshore phase, massive coral colonies suitable for paleoclimate studies and spanning most of the last deglacial sequence were recovered in the cores. During the Onshore Science Party, these massive coral colonies were slab-sampled for paleoclimate studies, the results of which are expected to fulfil the second objective.

\section{Analyze the impact of sea level changes on reef growth and geometry.}

During the offshore phase, cores were recovered from holes in various water depths and situated on transects in three different areas around Tahiti. Therefore, results of analyses of samples taken during the Onshore Science Party will be interpreted in broad temporal and spacial contexts and studies will consider a wide range of carbonate-secreting organisms as witnesses of ecologic change, which will allow better understanding of the development of the Tahiti reef.

\section{References}

Anderson, D.M., and Webb, R.S., 1994. Ice-age tropics revisited. Nature (London, U. K.), 367:23-24. doi:10.1038/367023a0

Anselmetti, F., and Eberli, G., 2001. Sonic velocity in carbonates: a combined product of depositional lithology and diagenetic alterations. In Ginsburg, R.N. (Ed.), Subsurface Geology of a Prograding Carbonate Platform Margin, Great Bahama Bank: Results of the Bahamas Drilling
Project. Spec. Publ._SEPM (Soc. Sediment. Geol.), 70:193-216.

Anselmetti, F.S., and Eberli, G.P., 1993. Controls on sonic velocity in carbonates. Pure Appl. Geophys., 141(24):287-323.

Bard, E., Hamelin, B., Arnold, M., Montaggioni, L., Cabioch, G., Faure, G., and Rougerie, F., 1996. Deglacial sea-level record from Tahiti corals and the timing of global meltwater discharge. Nature (London, U. K.), 382:241-244. doi:10.1038/382241a0

Bard, E., Hamelin, B., and Fairbanks, R.G., 1990a. U-Th ages obtained by mass spectrometry in corals from Barbados: sea level during the past 130,000 years. Nature (London, U. K.), 346:456-458. doi:10.1038/346456a0

Bard, E., Hamelin, B., Fairbanks, R.G., and Zindler, A., 1990b. Calibration of the ${ }^{14} \mathrm{C}$ timescale over the past 30,000 years using mass spectrometric U-Th ages from Barbados corals. Nature (London, U. K.), 345:405-410. doi:10.1038/345405a0

Bard, E., Rostek, F., and Sonzogni, C., 1997. Interhemispheric synchrony of the last deglaciation inferred from alkenone palaeothermometry. Nature (London, U. K.), 385:707-710. doi:10.1038/385707a0

Beck, J.W., Récy, J., Taylor, F., Edwards, R.L., and Cabioch, G., 1997. Abrupt changes in early Holocene tropical sea surface temperature derived from coral records. Nature (London, U. K.), 385:705-707. doi:10.1038/385705a0

Berner, R.A., 1980. Early Diagenesis: A Theoretical Approach: Princeton, NJ (Princeton Univ. Press).

Biot, M.A., 1956a. Theory of propagation of elastic waves in a fluid saturated porous solid, I. Low-frequency range. J. Acoust. Soc. Am., 28(2):168-178. doi:10.1121/ 1.1908239

Biot, M.A., 1956b. Theory of propagation of elastic waves in a fluid saturated porous solid, II. Higher frequency range. J. Acoust. Soc. Am., 28(2):179-191. doi:10.1121/ 1.1908241

Blanchon, P., and Shaw, J., 1995. Reef drowning during the last deglaciation: evidence for catastrophic sea-level rise and ice-sheet collapse. Geology, 23(1):4-8. doi: 10.1130/ 0091-7613(1995)023<0004:RDDTLD>2.3.CO;2

Braaksma, H., Kenter, J.A.M., Proust, J.N., Dijkmans, V., van Hoek, T., Mahieux, G., and Drijkoningen, G.G., 2003. Controls on acoustic properties of Upper Jurassic siliciclastic rocks (Boulonnais, northern France). Geophysics, 68(1):58-69. doi:10.1190/1.1543194

Broecker, W.S., 1990. Salinity history of the Northern Atlantic during the last deglaciation. Paleoceanography, 5:459-467.

Broecker, W.S., 1992. Defining the boundaries of the late glacial isotope episodes. Quat. Res., 38:135.

Camoin, G.F., Colonna, M., Montaggioni, L.F., Casanova, J., Faure, G., and Thomassin, B.A., 1997. Holocene sea level changes and reef development in the southwestern Indian Ocean. Coral Reefs, 16(4):247-259. doi: $10.1007 / \mathrm{s} 003380050080$

Chappell, J., and Polach, H., 1991. Post-glacial sea-level rise from a coral record at Huon Peninsula, Papua New 
Guinea. Nature (London, U. K.), 349:147-149. doi:10.1038/349147a0

Cheng, Q.C., Macdougall, J.D., and Lugmair, G.W., 1993. Geochemical studies of Tahiti, Teahitia and Mehetia, Society Island chain. J. Volcanol. Geotherm. Res., 55(12):155-184. doi:10.1016/0377-0273(93)90096-A

Dullo, W.C., Camoin, G.F., Blomeier, D., Colonna, M., Eisenhauer, A., Faure, G., Casanova, J., and Thomassin, B.A., 1998. Morphology and sediments of the foreslopes of Mayotte, Comoro Islands: direct observations from a submersible. In Camoin, G.F., and Davies, P.J., Reefs and Carbonate Platforms in the Pacific and Indian Oceans: Oxford (Blackwell), 219-236.

Duncan, R.A., Fisk, M.R., White, W.M., and Neilsen, R.L., 1994. Tahiti: geochemical evolution of a French Polynesian volcano. J. Geophys. Res., 99(B12):24341-24358. doi:10.1029/94JB00991

Eberli, G.P., 1991. Calcareous turbidites and their relationship to sea-level fluctuations and tectonism. In Einsele, G., Werner, R., and Seilacher, A. (Eds.), Cycles and Events in Stratigraphy: Berlin (Springer Verlag), 340-359.

Edwards, R.L., Beck, J.W., Burr, G.S., Donahue, D.J., Chappell, J.M.A., Bloom, A.L., Druffel, E.R.M., and Taylor, F.W., 1993. A large drop in atmospheric ${ }^{14} \mathrm{C} /{ }^{12} \mathrm{C}$ and reduced melting in the Younger Dryas, documented with ${ }^{230}$ Th ages of coral. Science, 260:962-968.

Fairbanks, R.G., 1989. A 17,000-year glacio-eustatic sea level record: influence of glacial melting rates on the Younger Dryas event and deep-ocean circulation. Nature (London, U. K.), 342:637-642. doi:10.1038/342637a0

Fleming, K., Johnston, P., Zwartz, D., Yoyoyama, Y., Lambeck, K., and Chapell, J., 1998. Refining the eustatic sealevel curve since the Last Glacial Maximum using farand intermediate-field sites. Earth Planet. Sci. Lett., 163(1-4):327-342. doi:10.1016/S0012-

821X(98)00198-8

Gagan, M.K., Ayliffe, L.K., Hopley, D., Cali, J.A., Mortimer, G.E., Chappell, J., McCulloch, M.T., and Head, M.J., 1998. Temperature and surface-ocean water balance of the mid-Holocene tropical western Pacific. Science, 279:1014-1018. doi:10.1126/science.279.5353.1014

Gassmann, F., 1951. Über die Elastizität Poröser Medien. Vierteljahrsschr. Naturforsch. Ges. Zuerich, 96:1-23.

Grammer, G.M., and Ginsburg, R.N., 1992. Highstand versus lowstand deposition on carbonate platform margins: insight from Quaternary foreslopes in the Bahamas. Mar. Geol., 103(1-3):125-136. doi:10.1016/ 0025-3227(92)90012-7

Grootes, P.M., Stuiver, M., White, J.W.C., Johnsen, S., and Jouzel, J., 1993. Comparison of oxygen isotope records from the GISP2 and GRIP Greenland ice cores. Nature (London, U. K.), 366:552-554. doi:10.1038/366552a0

Guilderson, T.P., Fairbanks, R.G., and Rubenstone, J.L., 1994. Tropical temperature variations since 20,000 years ago: modulating interhemispheric climate change. Science, 263:663-665. doi:10.1126/science.263.5147.663

Johnsen, S.J., Clausen, H.B., Dansgaard, W., Fuhrer, K., Gundestrup, N., Hammer, C.U., Iversen, P., Jouzel, J., Stauffer, B., and Steffensen, J.P., 1992. Irregular glacial interstadials recorded in a new Greenland ice core.
Nature (London, U. K.), 359:311-313. doi:10.1038/ $359311 \mathrm{a} 0$

Jordan, C., and Wilson, J.L., 1998. Reefs: geologic considerations for geophysicists. Leading Edge, 17(3):325-238. doi:10.1190/1.1437964

Kenter, J.A.M., Fouke, B.W., and Reinders, M., 1997. Effects of differential cementation on the sonic velocities of Late Cretaceous skeletal grainstones (southeastern Netherlands). J. Sediment. Res., 67:178-185.

Lambeck, K., 1993. Glacial rebound and sea-level change: an example of a relationship between mantle and surface processes. In Wortel, M.J.R., Hansen, U., and Sabadini, R. (Eds.), Relationships between Mantle Processes and Geologic Processes at or near the Earth's Surface: Amsterdam (Elsevier), 15-37.

Lindstrom, D.R., and MacAyeal, D.R., 1993. Death of an ice sheet. Nature (London, U. K.), 365:214-215. doi:10.1038/365214a0

Locker, S.D., Hine, A.C., Tedesco, L.P., and Shinn, E.A., 1996. Magnitude and timing of episodic sea-level rise during the last deglaciation. Geology, 24:827-830. doi:10.1130/00917613(1996)024<0827:MATOES>2.3.CO;2

McBirney, A.R., and Aoki, K., 1968. Petrology of the island of Tahiti. Mem.-Geol. Soc. Am., 116:523-556.

McCulloch, M., Mortimer, G., Esat, T., Xianhua, L., Pillans, B., and Chappell, J., 1996. High resolution windows into early Holocene climate: Sr/Ca coral records from the Huon Peninsula: Earth Planet. Sci. Lett., 138(14):169-178. doi:10.1016/0012-821X(95)00230-A

McCulloch, M.T., Tudhope, A.W., Esat, T.M., Mortimer, G.E., Chappell, J., Pillans, B., Chivas, A.R., and Omura, A., 1999. Coral record of equatorial sea-surface temperatures during the penultimate deglaciation at Huon Peninsula. Science, 283:202-204. doi:10.1126/ science.283.5399.202

MacIntyre, I.G., Rützler, K., Norris, J.N., Smith, K.P., Cairns, S.D., Bucher, K.E., and Steneck, R.S., 1991. An early Holocene reef in the western Atlantic: submersible investigations of a deep relict reef off the west coast of Barbados, W.I. Coral Reefs, 10(3):167-174. doi:10.1007/ BF00572177

Okuno, J., and Nakada, M., 1999. Total volume and temporal variation of meltwater from Last Glacial Maximum inferred from sea-level observations at Barbados and Tahiti. Palaeogeogr., Palaeoclimatol., Palaeoecol., 146(14):283-293. doi:10.1016/S0031-0182(98)00136-9

Parkhurst, D.L., and Appelo, C.A.J., 1999. User's guide to PHREEQC (version 2) - a computer program for speciation, batch-reaction, one-dimensional transport and inverse geochemical calculations. Water-Resour. Invest. Rep. (U.S. Geol. Surv.), 99-259.

Peltier, W.R., 1994. Ice age paleotopography. Science, 265:195-201. doi:10.1126/science.265.5169.195

Raymer, L.L., Hunt, E.R., and Gardner, J.S., 1980. An improved transit-to-porosity transform. SPWLA 21 Ann. Logging Symp.: 1-12.

Rind, D., and Peteet, D., 1985. Terrestrial conditions at the Last Glacial Maximum and CLIMAP sea-surface temper- 
ature estimates: are they consistent? Quat. Res., 24:1-22. doi:10.1016/0033-5894(85)90080-8

Stafleu, J., Everts, A.J.W., and Kenter, J.A.M., 1994. Seismic models of a prograding carbonate platform: Vercors, South-east France. Mar. Pet. Geol., 11(5):514-537. doi:10.1016/0264-8172(94)90065-5

Stocker, T.F., and Wright, D.G., 1991. Rapid transitions of the ocean's deep circulation induced by changes in surface water fluxes. Nature (London, U. K.), 351:729-732. doi:10.1038/351729a0

Troedson, A.L., and Davies, P.J., 2001. Contrasting facies patterns in subtropical and temperate continental slope sediments: inferences from east Australian late Quaternary records. Mar. Geol., 172(3-4):265-285. doi:10.1016/S0025-3227(00)00132-8

Wilson, J.L., 1975. Carbonate Facies in Geologic History: Berlin (Springer-Verlag).

Wyllie, M.R.J., Gregory, A.R., and Gardner, G.H.F., 1958. An experimental investigation of factors affecting elas- tic wave velocities in porous media. Geophysics, 23:459493.

Wyllie, M.R.J., Gregory, A.R., and Gardner, L.W., 1956. Elastic wave velocities in heterogeneous and porous media. Geophysics, 21(1):41-70. doi:10.1190/1.1438217

Zhang, L., Chan, L.-H., and Gieskes, J.M., 1998. Lithium isotope geochemistry of pore waters from Ocean Drilling Program Sites 918 and 919, Irminger Basin. Geochim. Cosmochim. Acta, 62(14):2437-2450. doi:10.1016/S0016-7037(98)00178-1

Zinke, J., Pfeiffer, M., Davies, G.R., Dullo, W.-C., and Camoin, G.F., 2005. First evidence of mid-Holocene and last interglacial seasonality in the tropical western Indian Ocean from corals [European Geosciences Union General Assembly 2005, Vienna, 24-29 April 2005].

Publication: 4 March 2007

MS 310-101 
Figure F1. A. Sea level history reconstructed for long drill cores from Tahiti (squares), Barbados (circles), and New Guinea (triangles) (from Bard et al., 1996). B. Reconstructed sea-surface temperatures for various time windows on corals from Vanuatu (Beck et al., 1997). MWP = meltwater pulse.

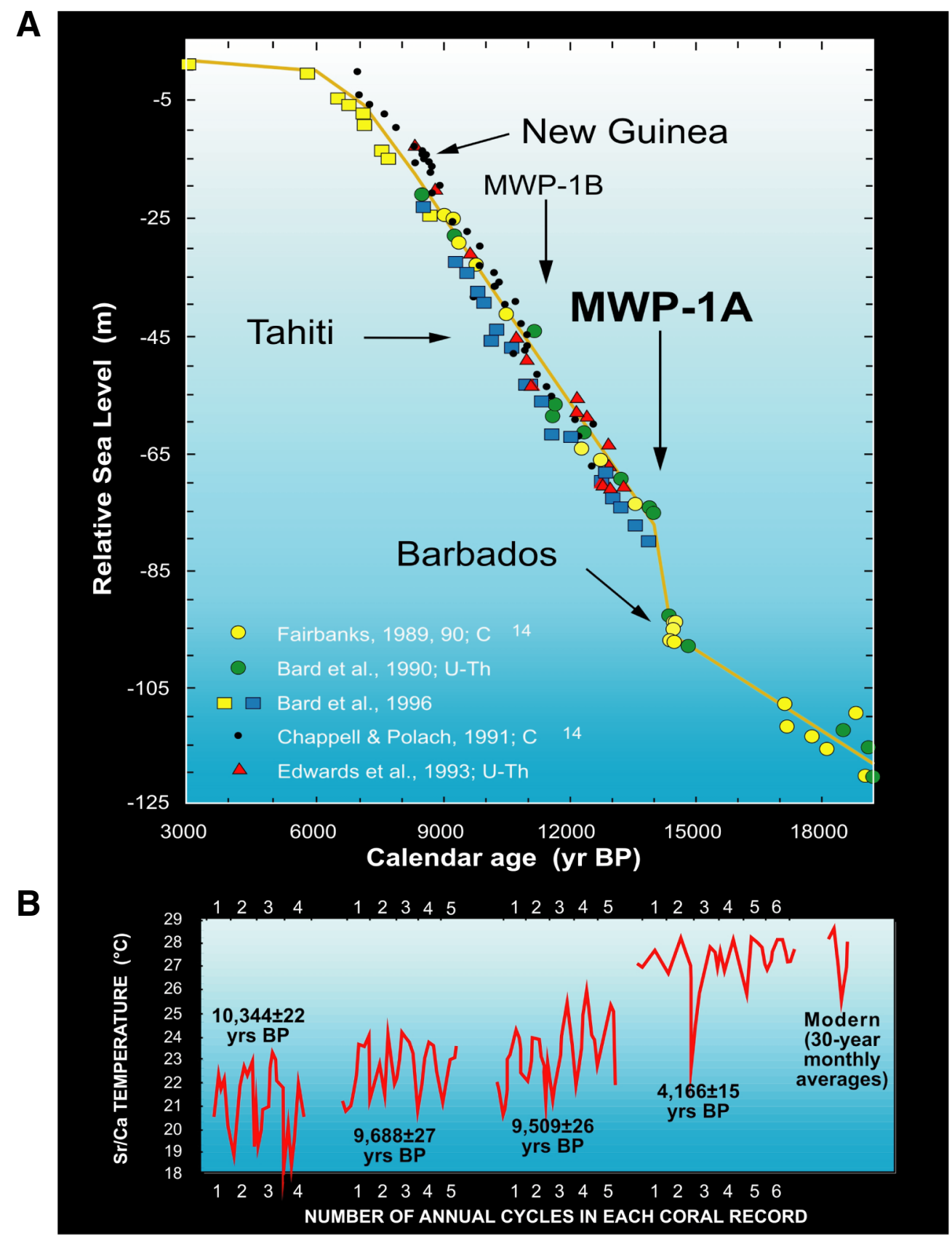


Figure F2. Location of Expedition 310 operations areas around Tahiti.

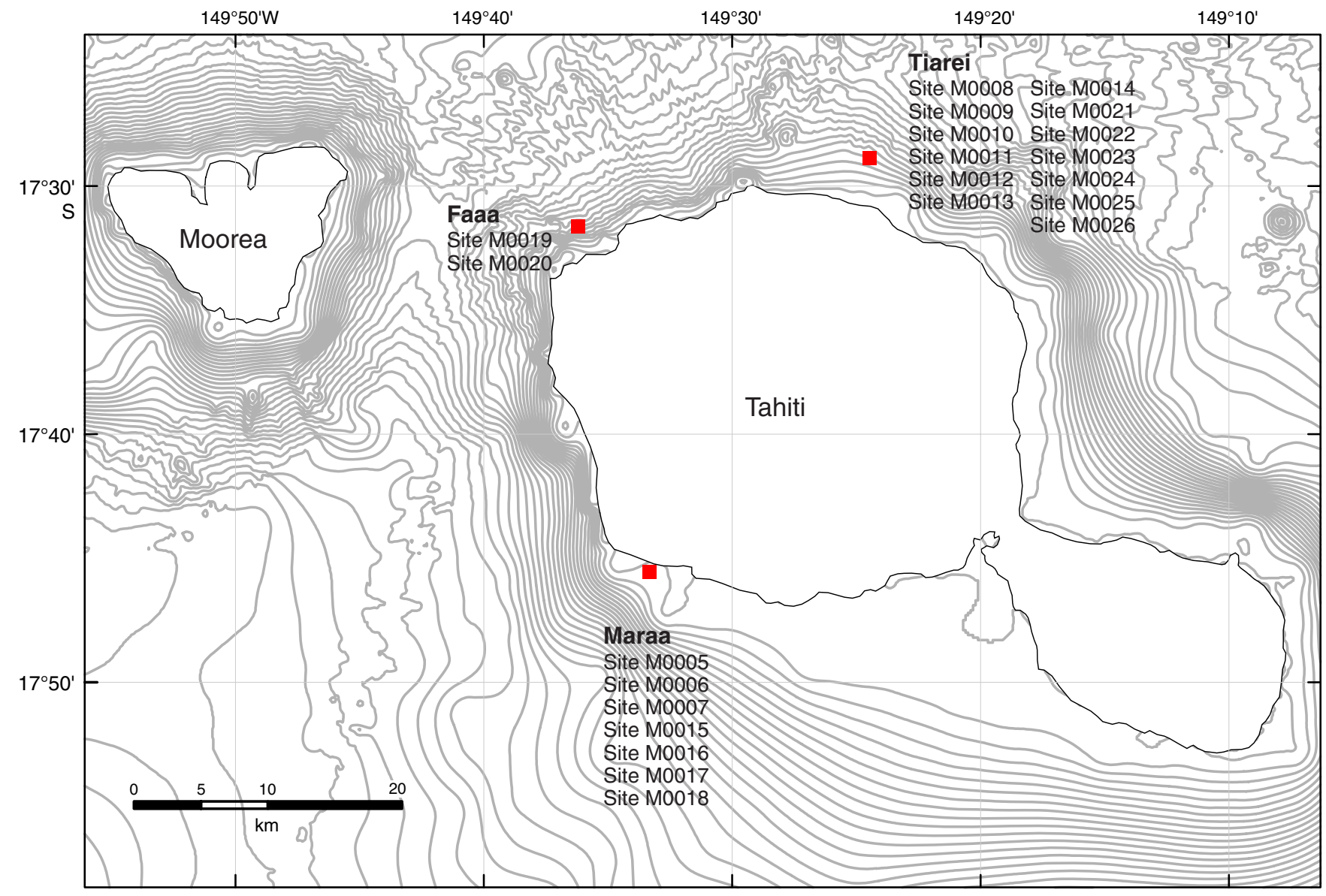


Figure F3. Location of Expedition 310 holes in the Faaa area (see Fig. F2 for location with respect to Tahiti).

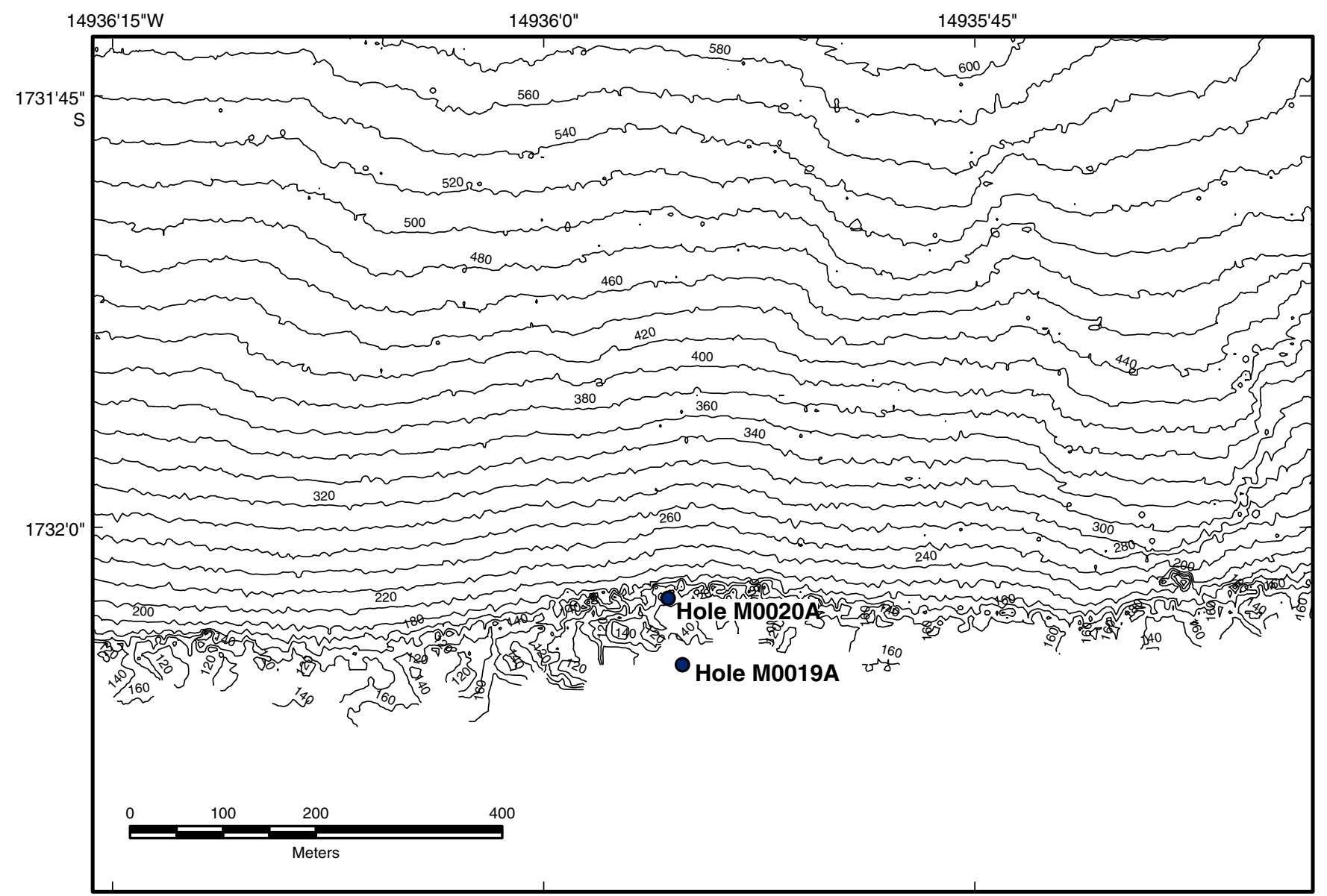


Figure F4. Location of Expedition 310 Holes in the Tiarei area (see Fig. F2 for location with respect to Tahiti).

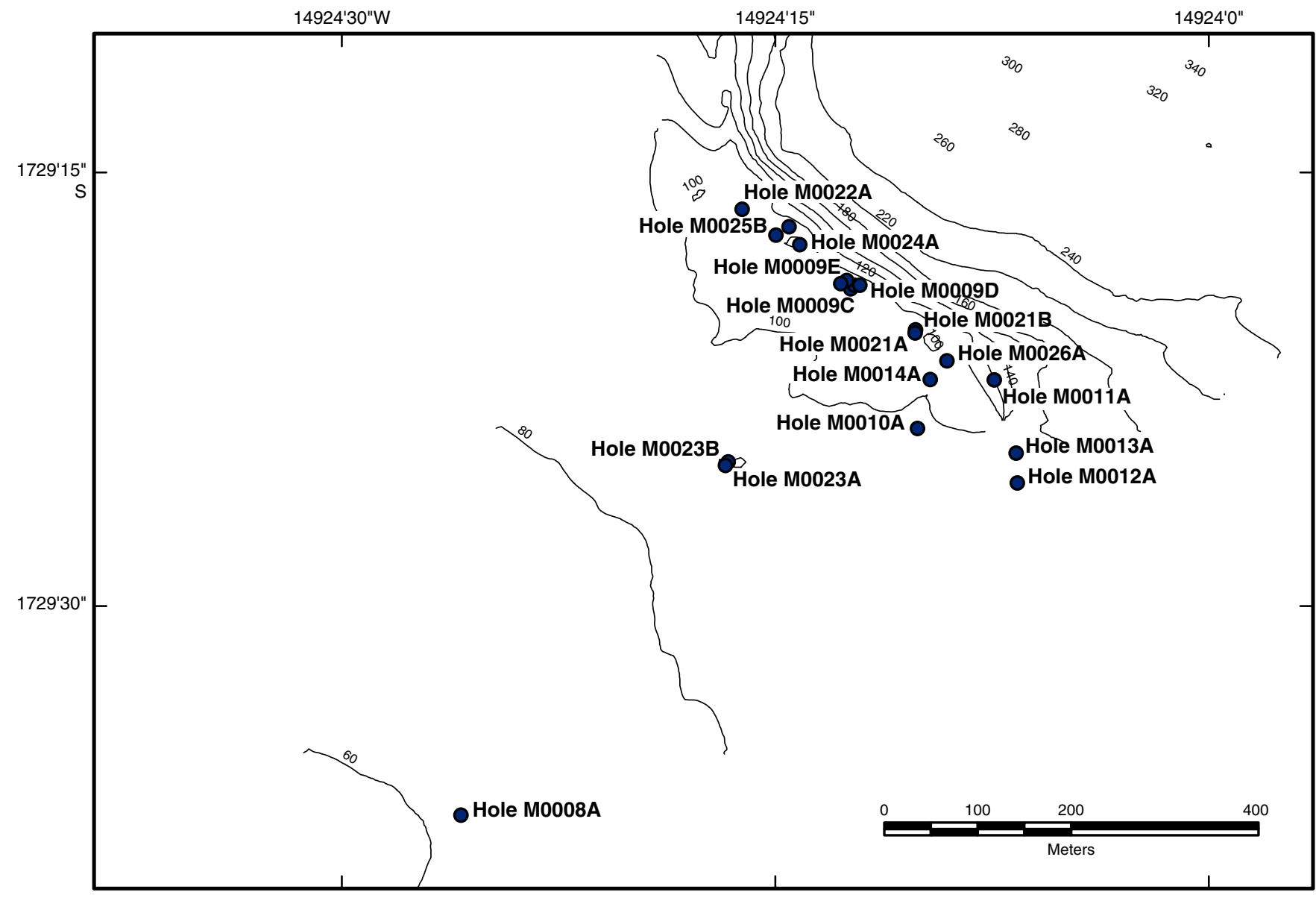


Figure F5. Location of Expedition 310 Holes in the Maraa area (see Fig. F2 for location with respect to Tahiti).

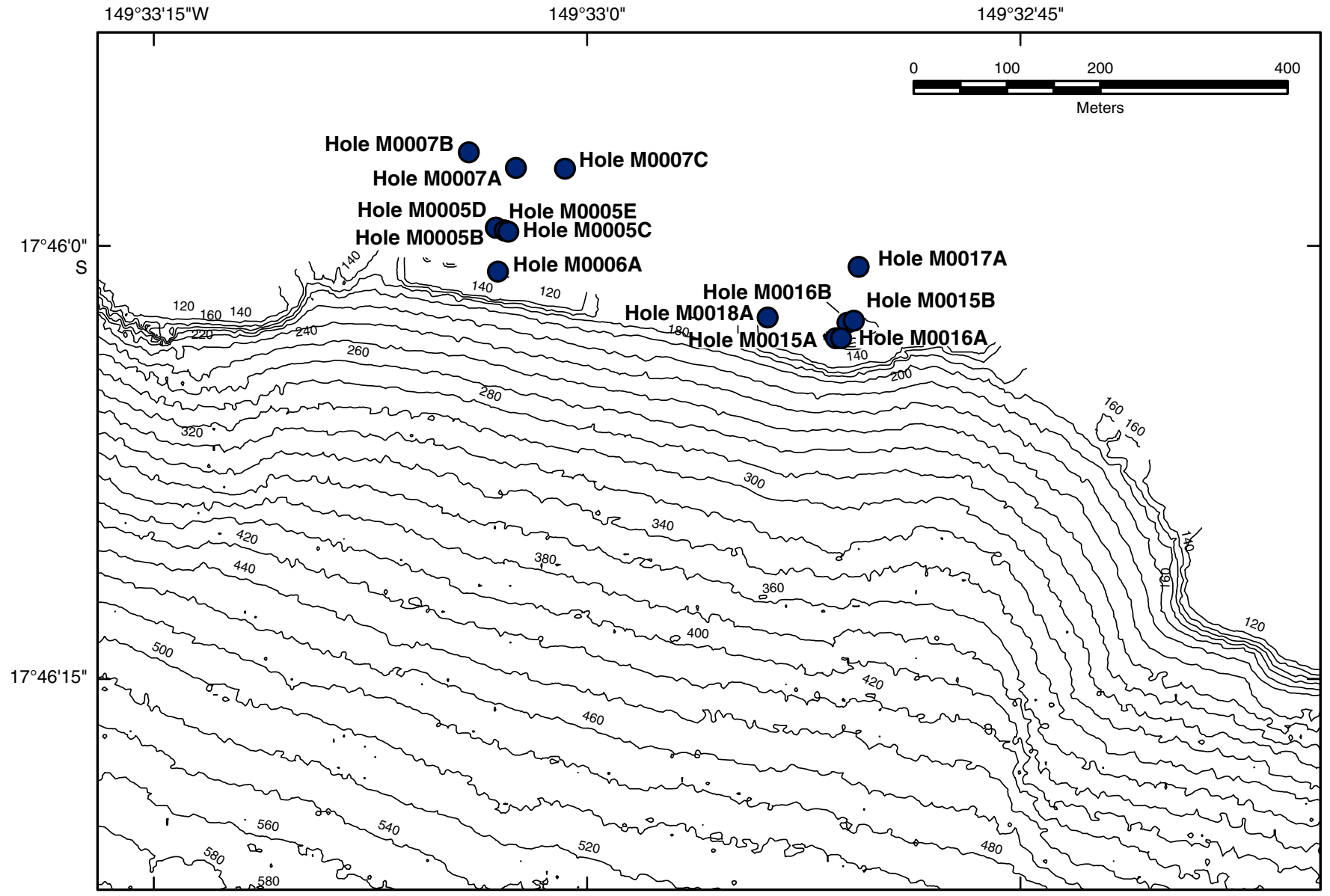


Figure F6. Lithostratigraphic summary of holes on the Maraa western transect. A. Holes M0007B, M0007A, and M0007C. (Continued on next page.)

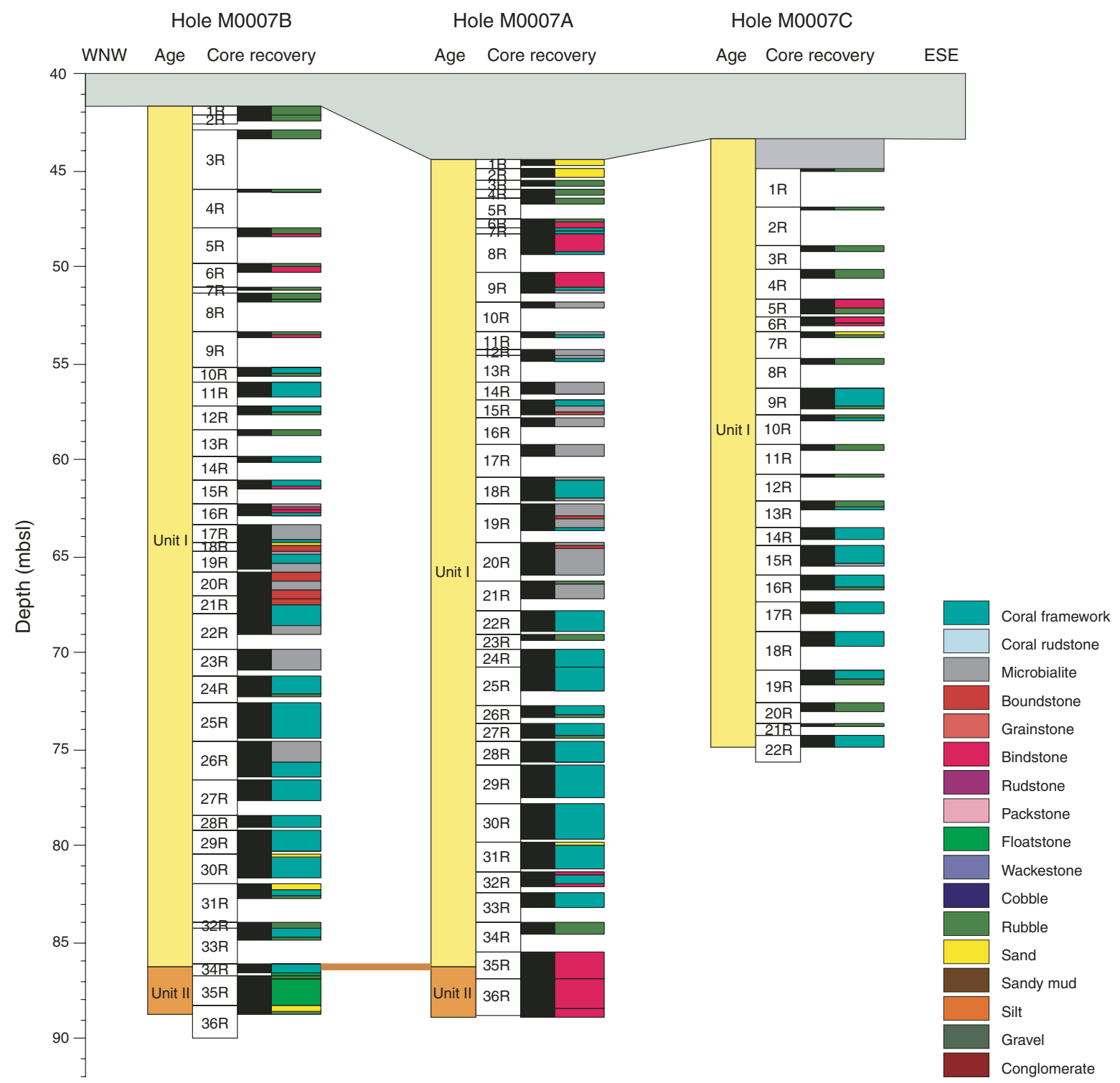


Figure F6 (continued). B. Holes M0005A, M0005B, M0005C, M0005D, M0005E, and M0006A.

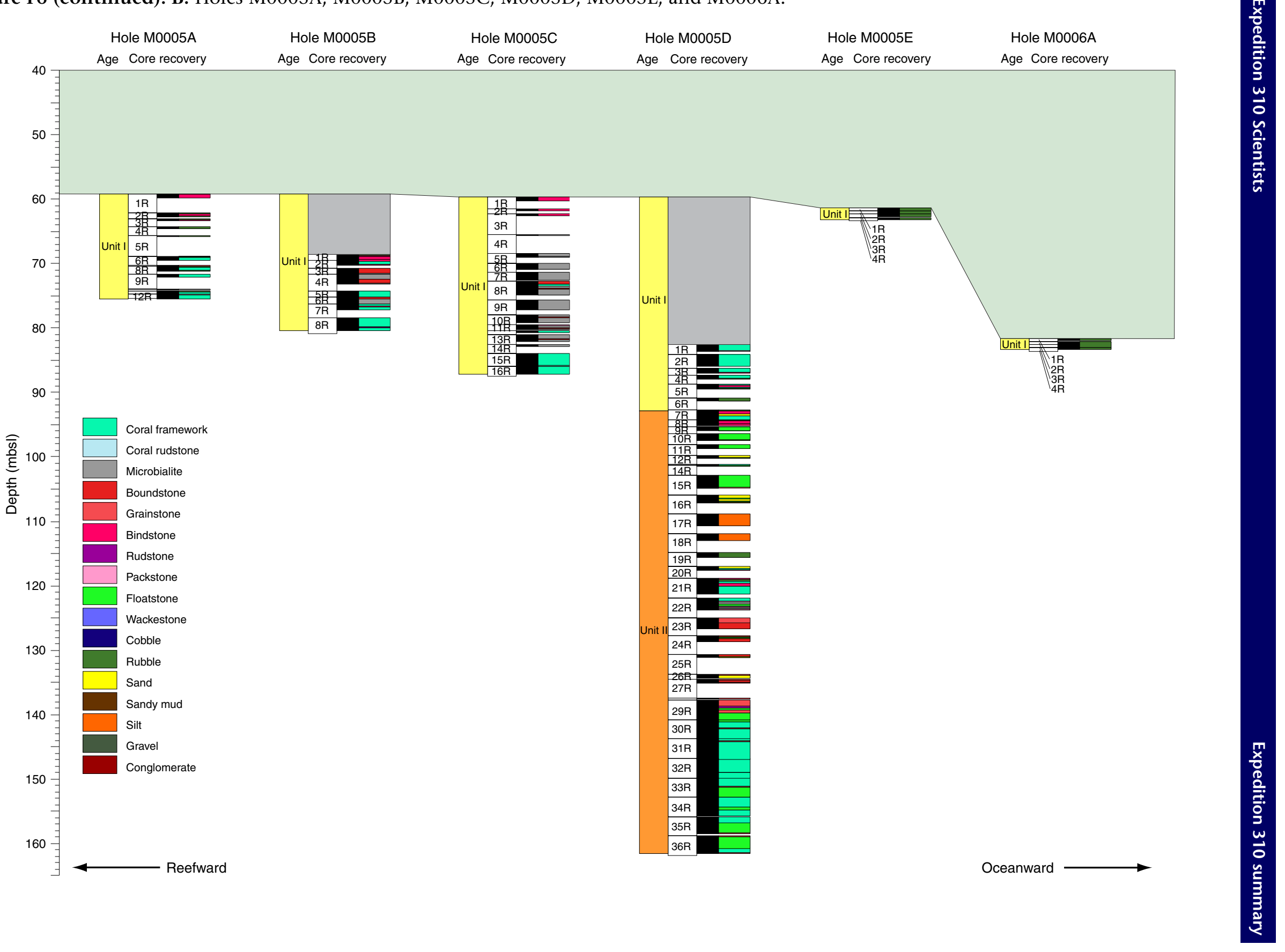



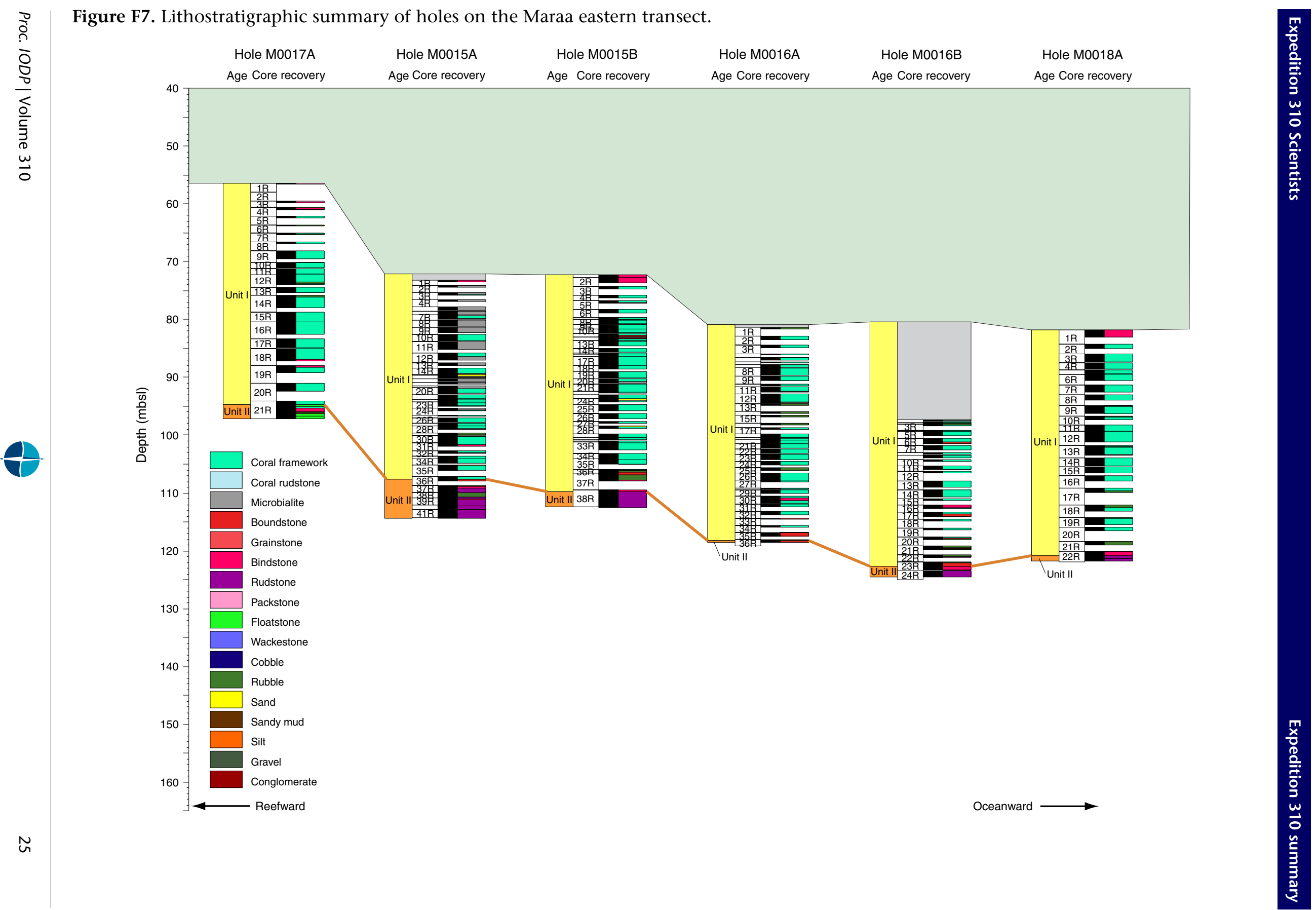
Figure F8. Lithostratigraphic summary of holes on the Tiarei inner ridge.

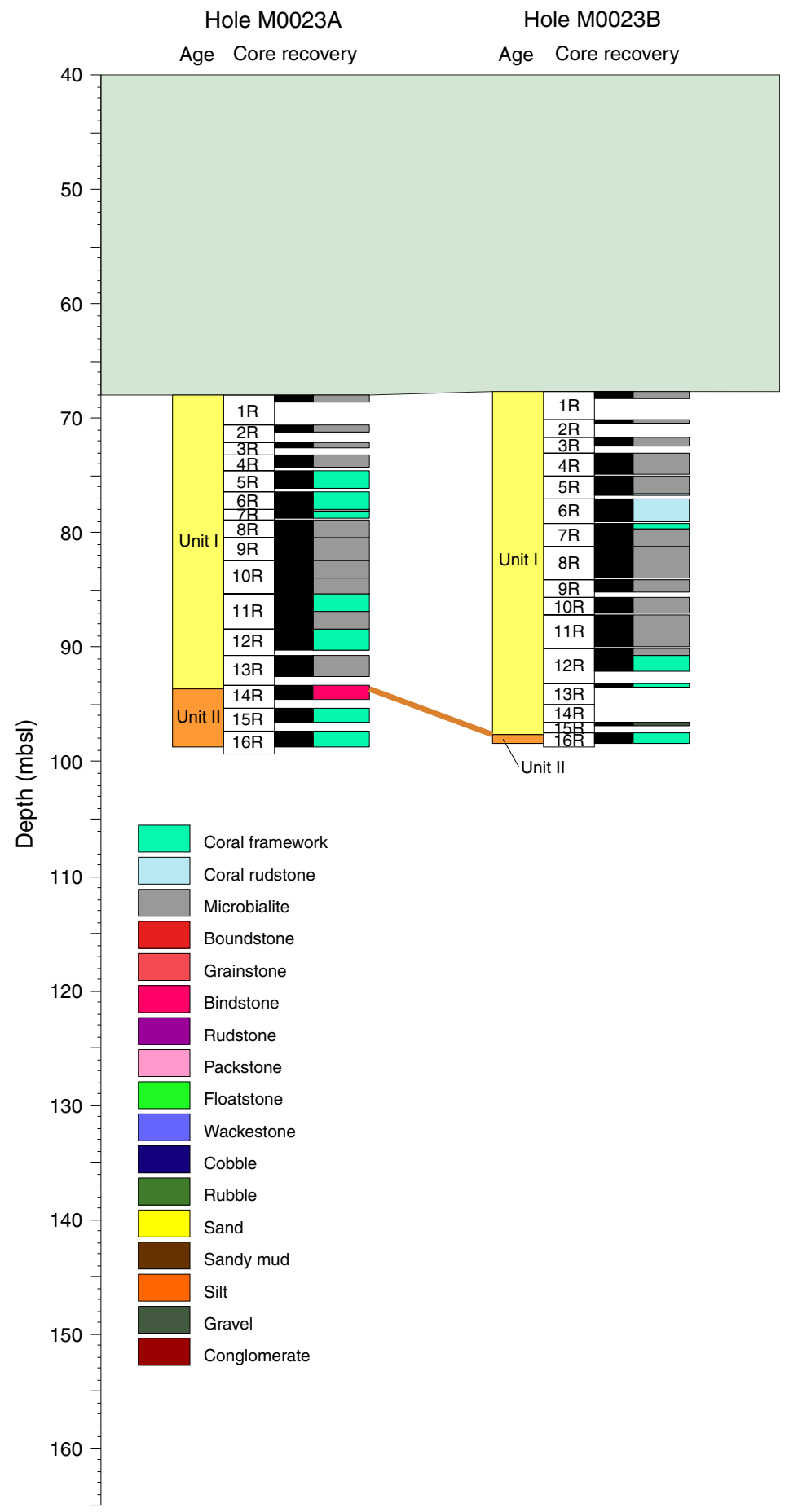


Figure F9. Lithostratigraphic summary of Holes on the Tiarei outer ridge. A. Holes M0009D, M0009E, M0024A, M0025A, and M0025B. (Continued on next page.)

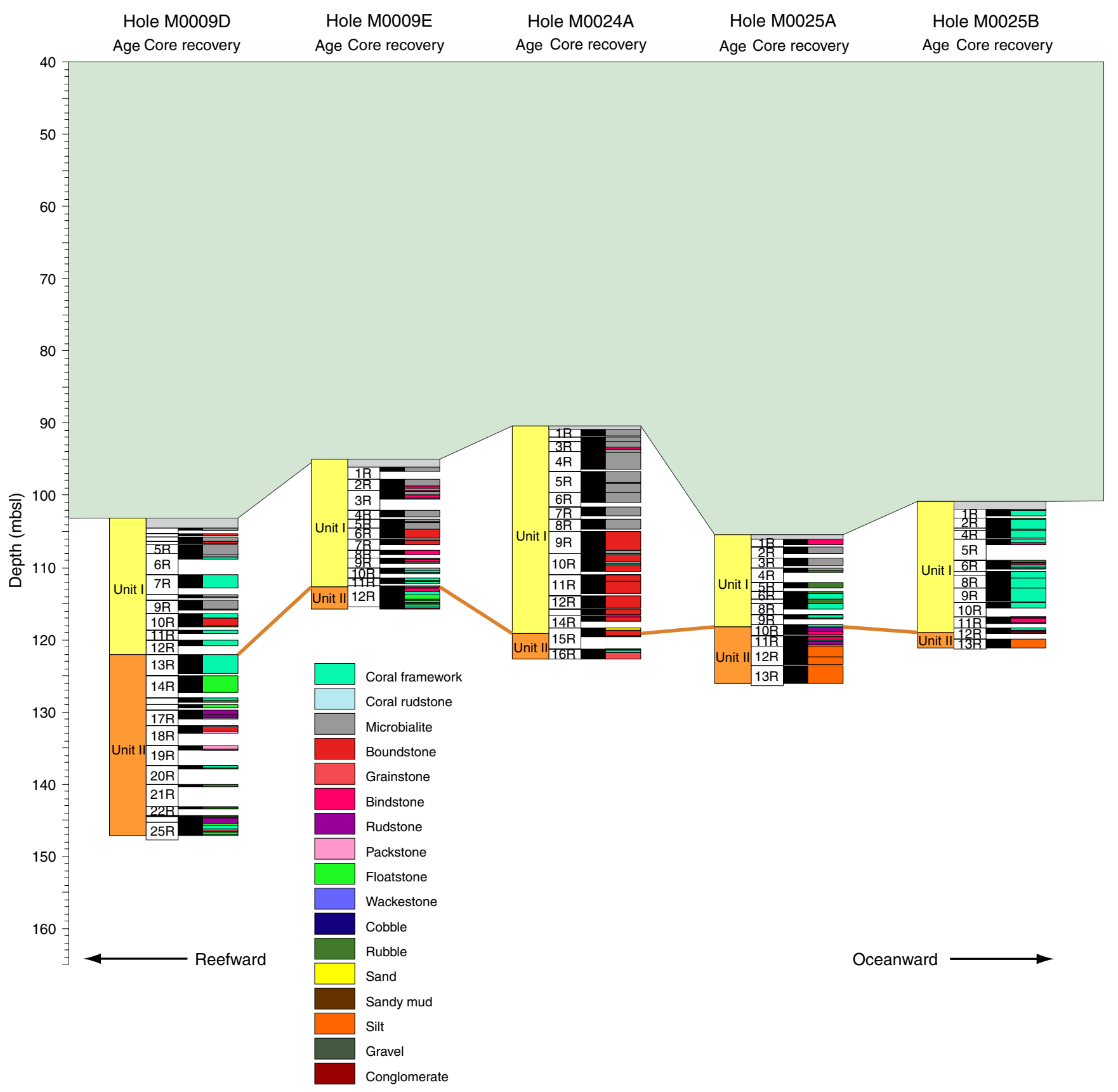



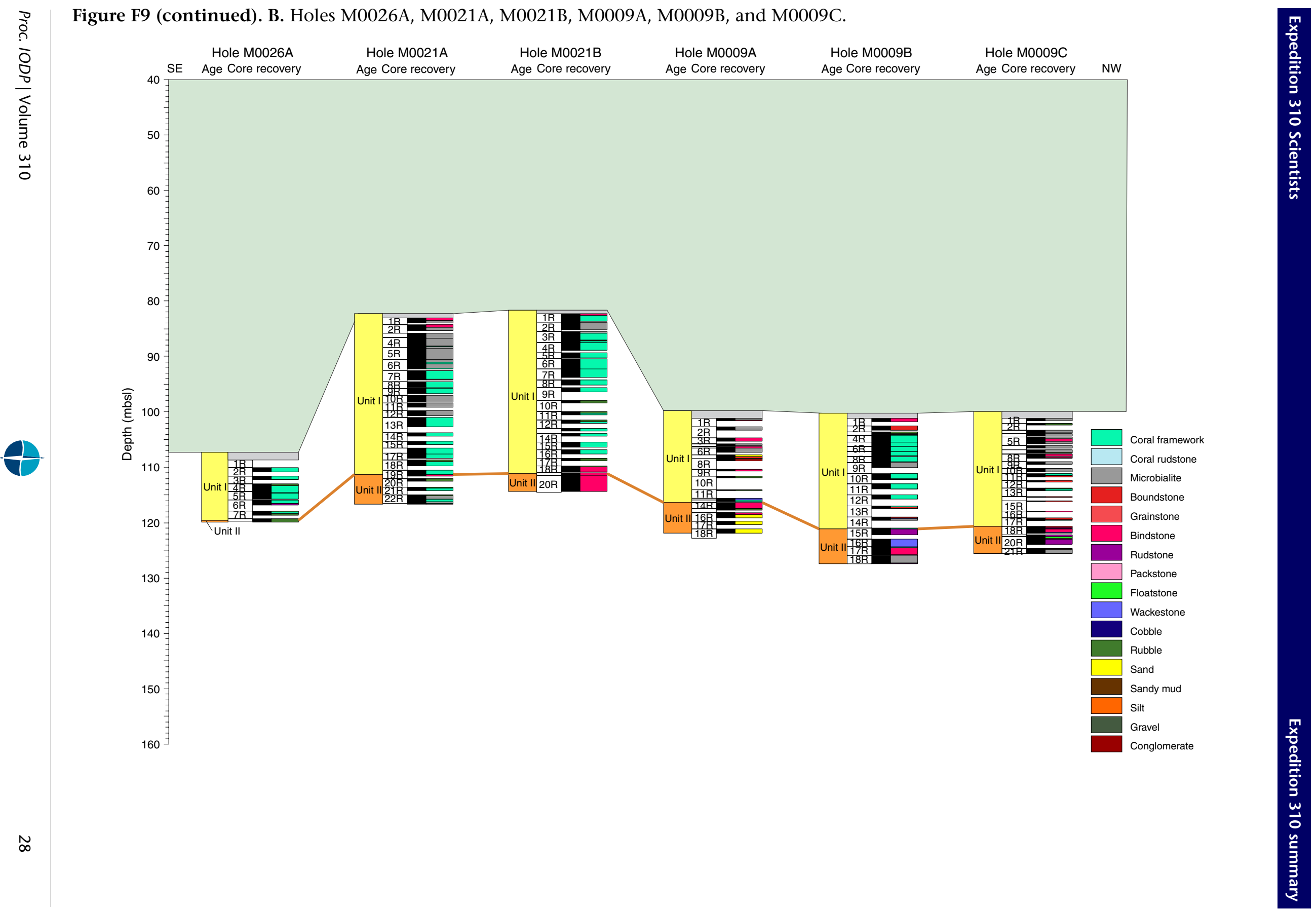
Figure F10. Lithostratigraphic summary of holes of the Tiarei marginal sites.

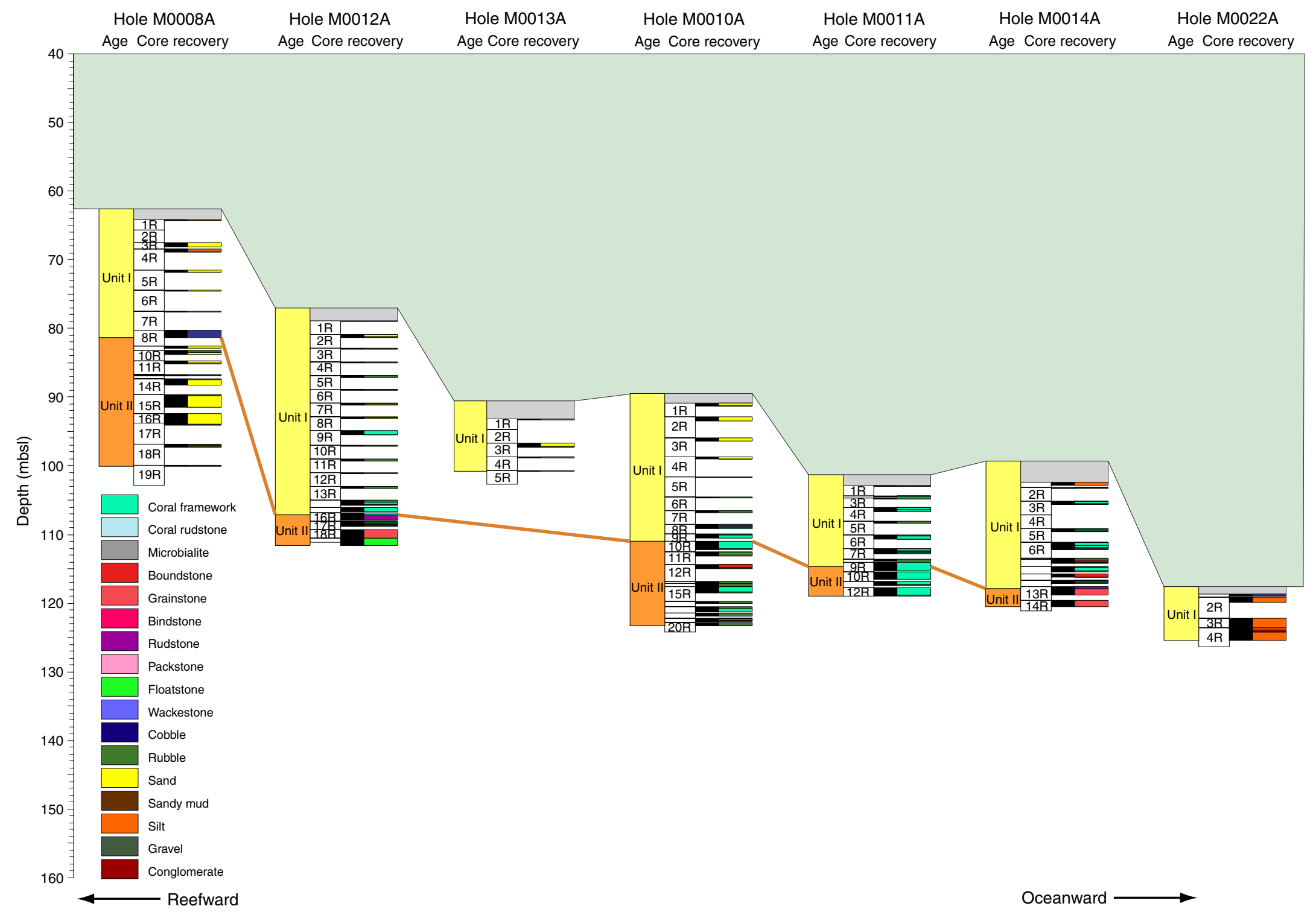


Figure F11. Lithostratigraphic summary of holes in the Faaa area.

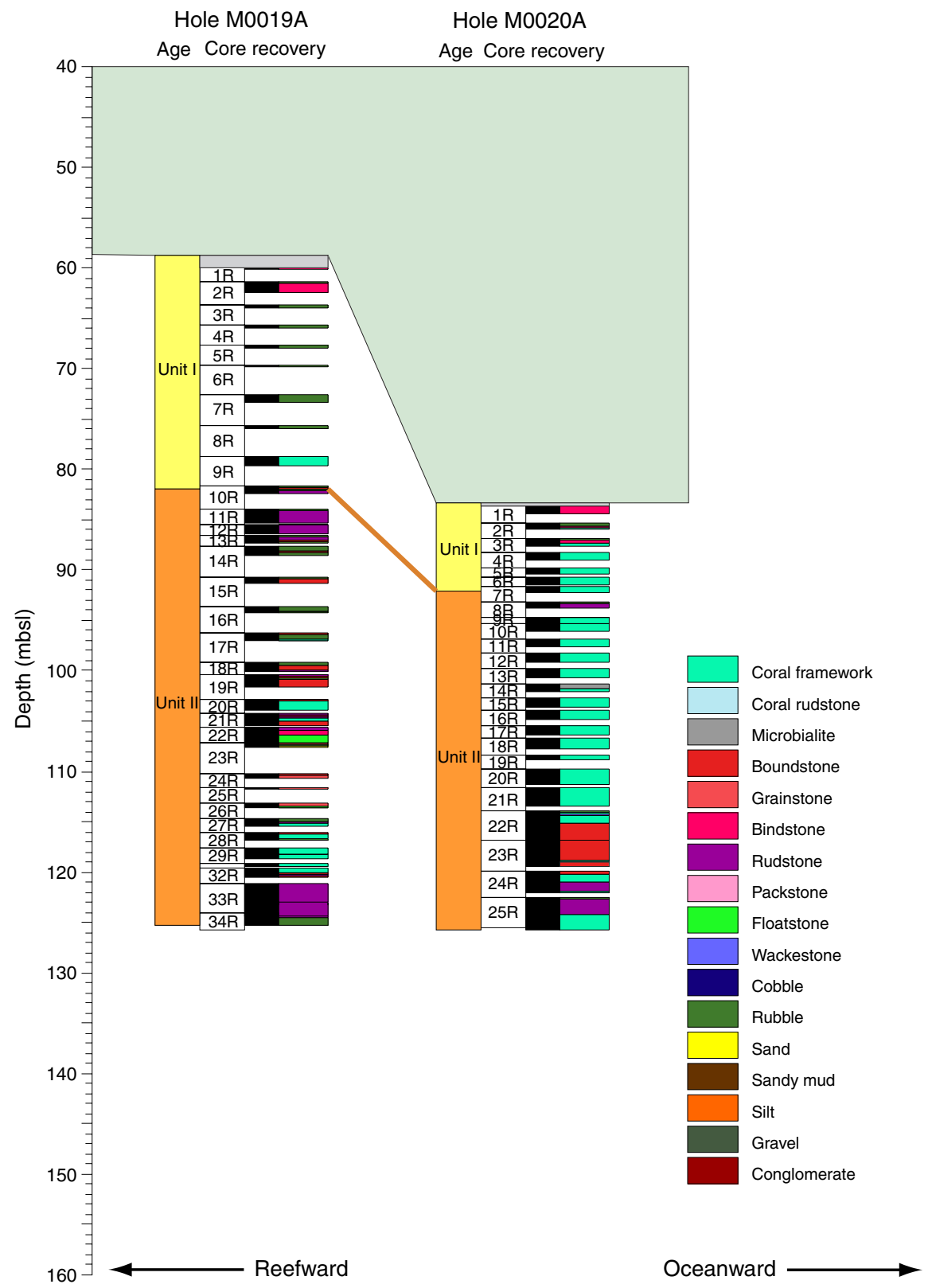


Figure F12. Cross plot showing all physical property data in the porosity and $P$-wave velocity domain. Instead of showing individual data points for the bulky MSCL data $(15,191$ data points), data density was contoured by moving a bin size of $0.200 \mathrm{~km} / \mathrm{s}$ by 0.02 porosity units diagonally with increments of $1 / 30$ of one bin size. Data density increases from blue to red. Purple $=$ discrete sample properties $(N=355)$. In addition, commonly used velocity transforms, like those by Raymer et al. (1980) and Wyllie et al. (1956), are superimposed.

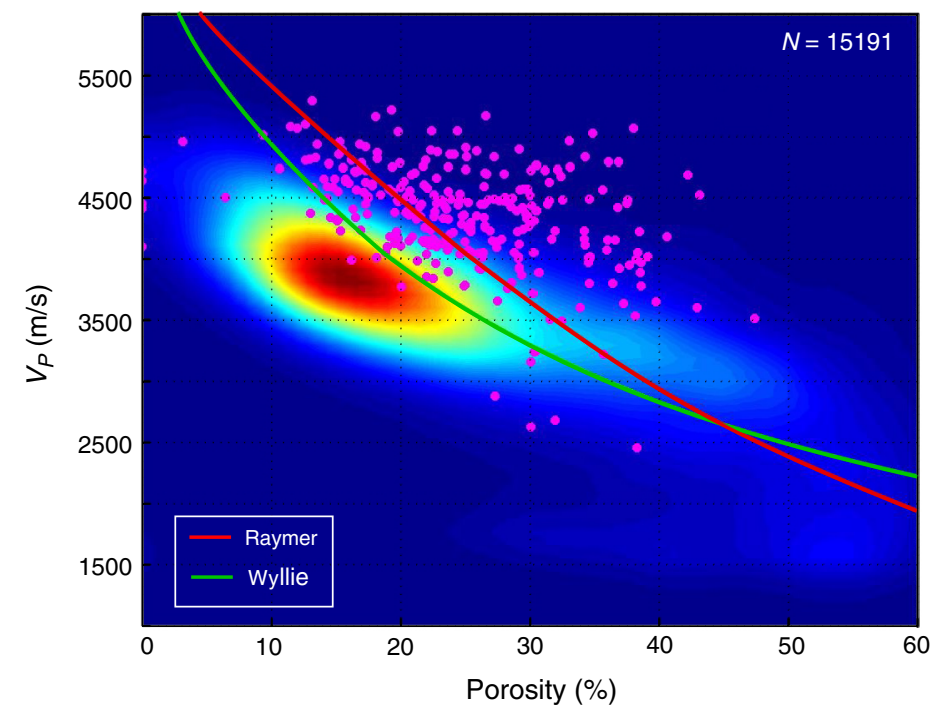


Figure F13. Brown iron/manganese crust and cavity (Hole M0016B; 23.68 mbsf).

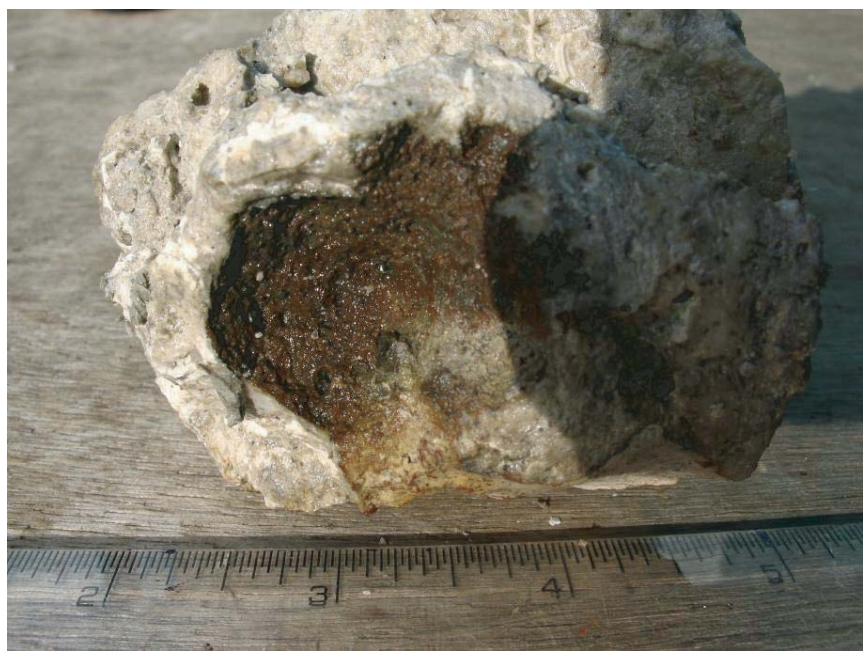


Figure F14. Blue/purple biofilm with high microbial activity and high abundance of cells (Hole M0015B; 0.47 mbsf).

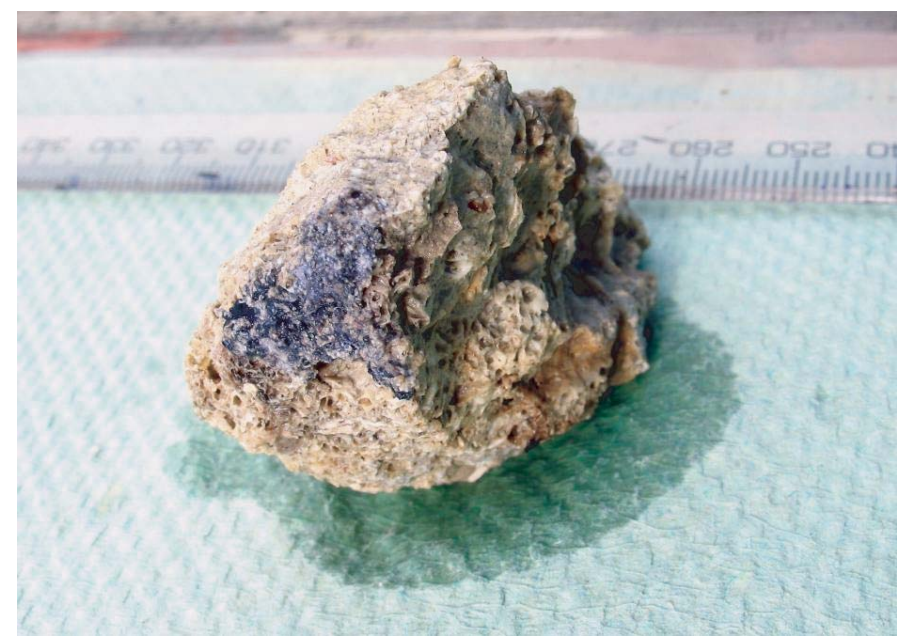


Figure F15. High abundance of cells in a biofilm (Hole M0015B; 0.47 mbsf; DAPI-stained fluorescence microscopy). 
Figure F16. Surface of microbialites with some fiber type minerals, most probably clay minerals (Hole M0007C; 5.88 mbsf; glutaraldehyde fixed SEM at 30,000×).

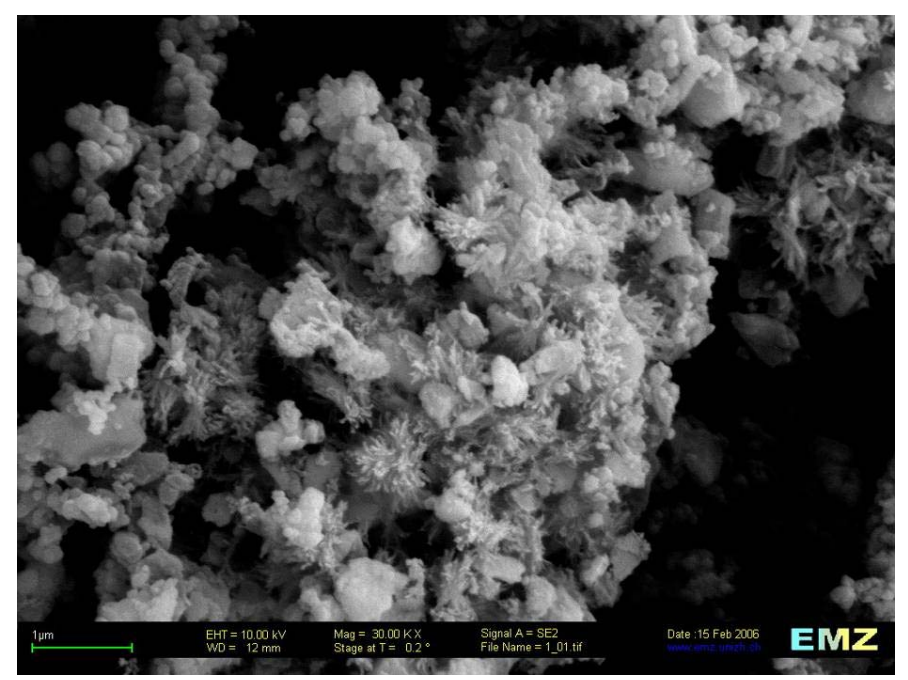


Figure F17. Surface of blue biofilm covered with a network of desiccated exopolymeric substances, minerals, probably carbonates, and microorganisms (Hole M0015B; 0.47 mbsf; glutaraldehyde fixed SEM at 19,200×).

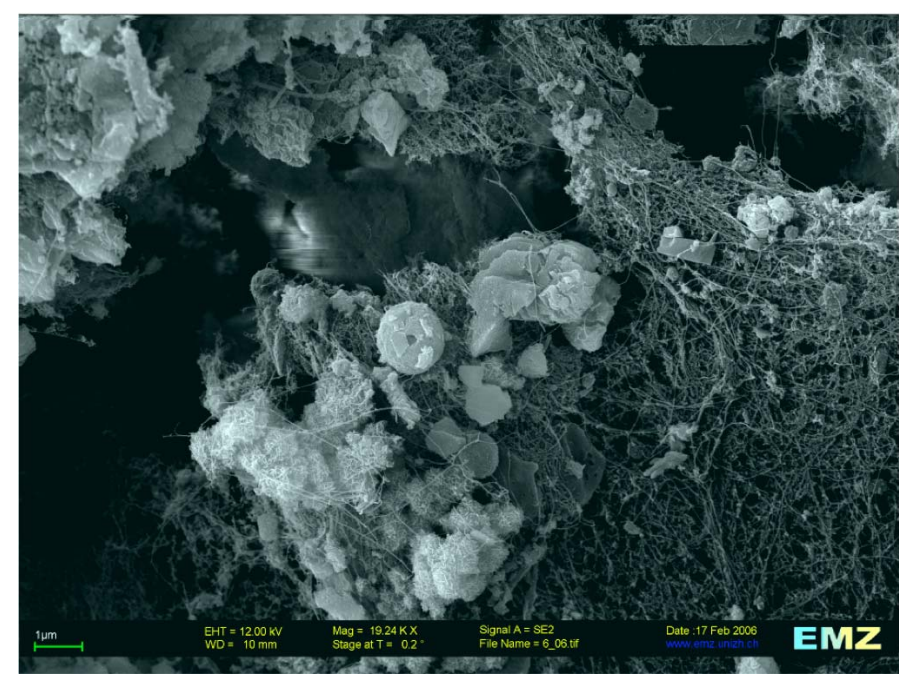


Figure F18. Surface of microbialites with framboidal pyrite crystals (Hole M0023A; 0.12 mbsf; glutaraldehyde fixed SEM at 9550×).

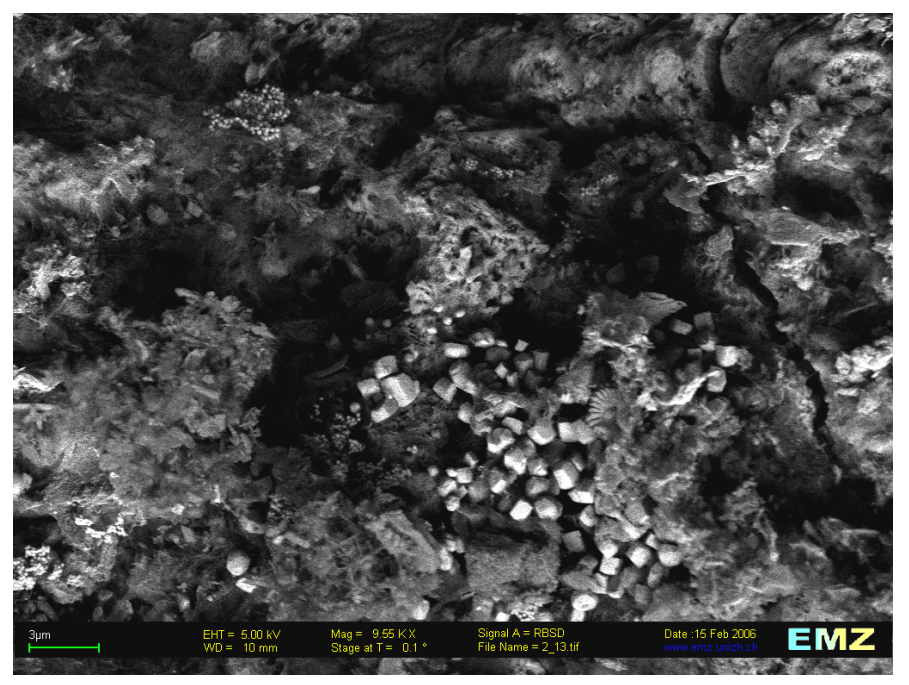


Figure F19. Rather high diversity of cell morphologies. Cells were common in this sample (Hole M0007C; 5.88 mbsf; DAPI-stained fluorescence microscopy).

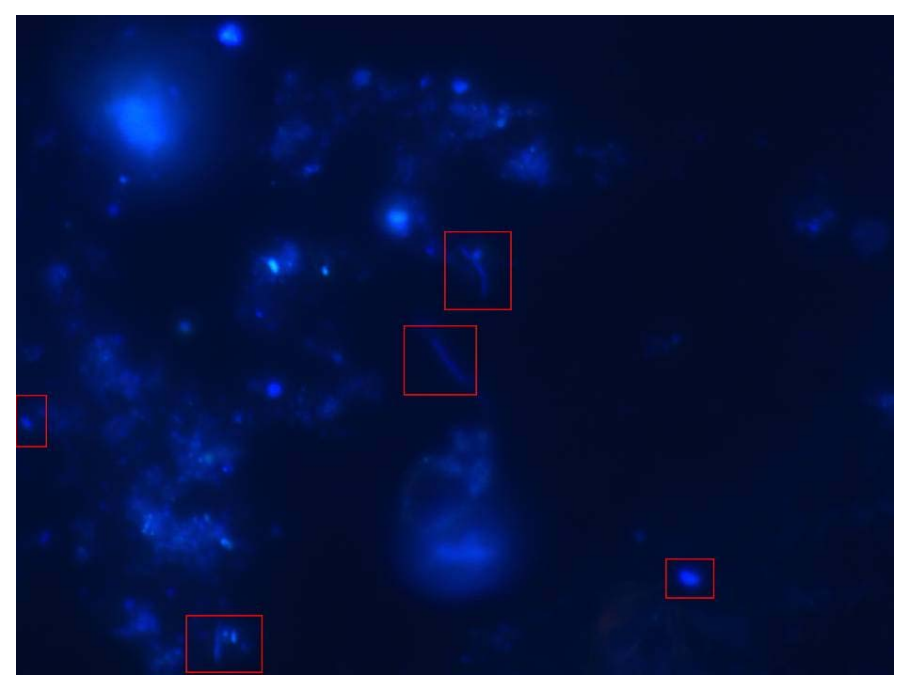


Figure F20. Interstitial water chemistry for Hole M0008A, showing depth profiles for (A) pH, (B) alkalinity, (C) ammonia, (D) potassium, (E) calcium, (F) strontium, (G) manganese, and (H) iron.
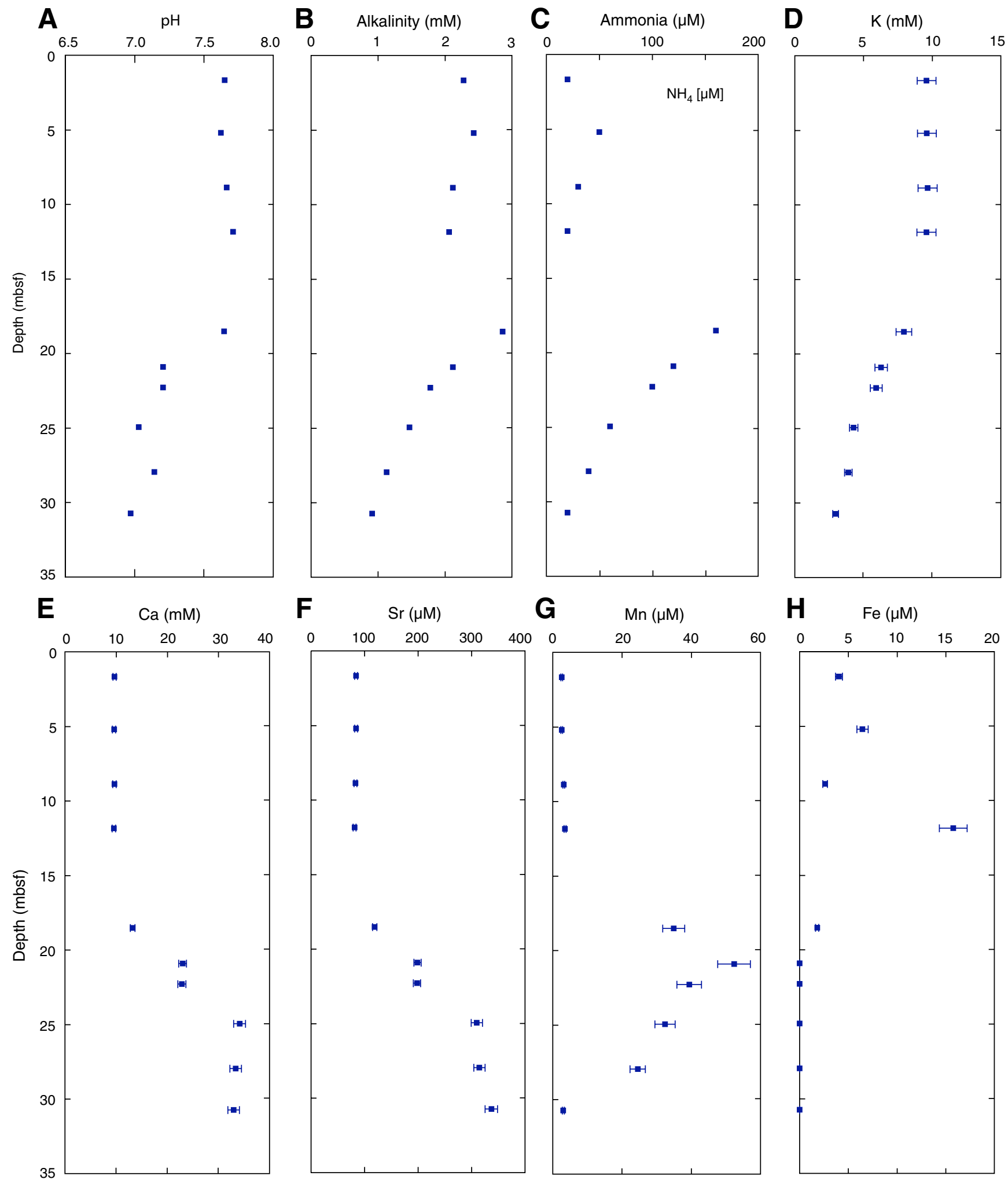

$\mathbf{F}$

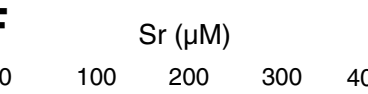

G
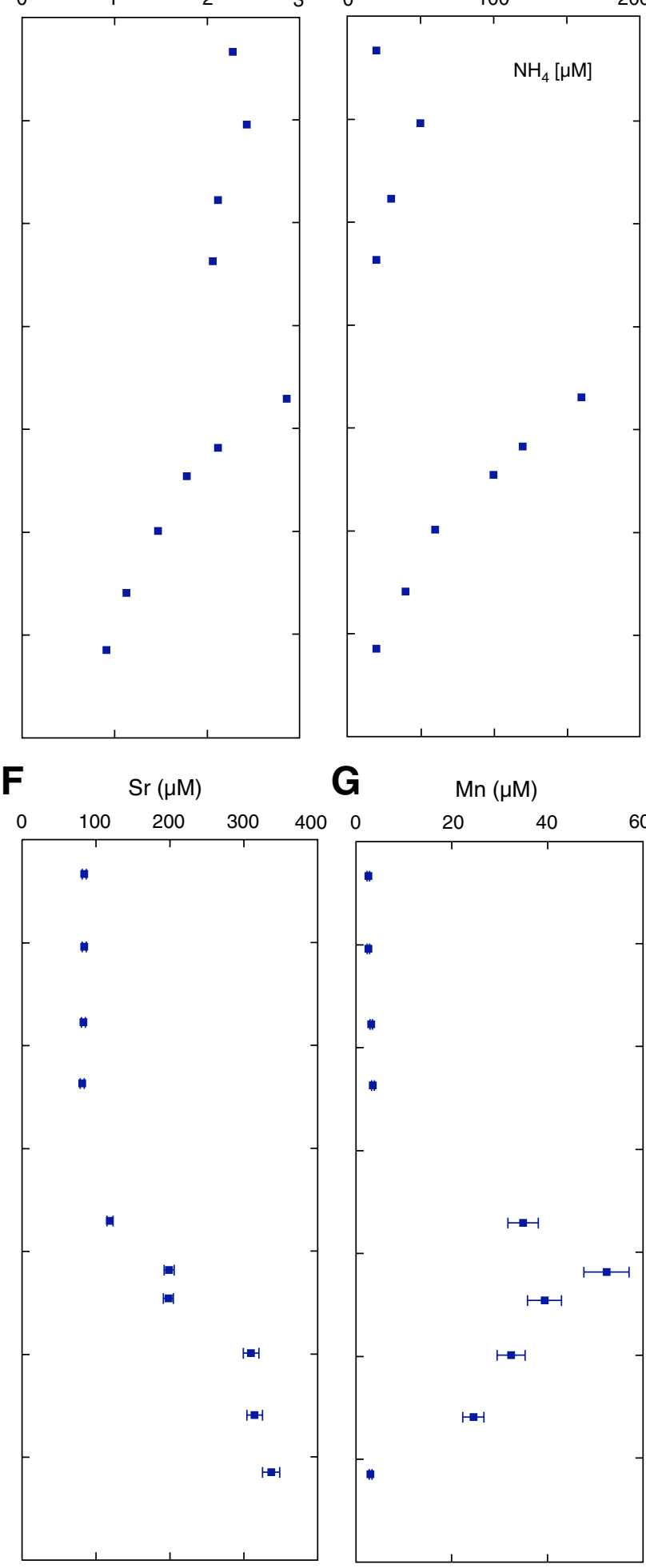

H
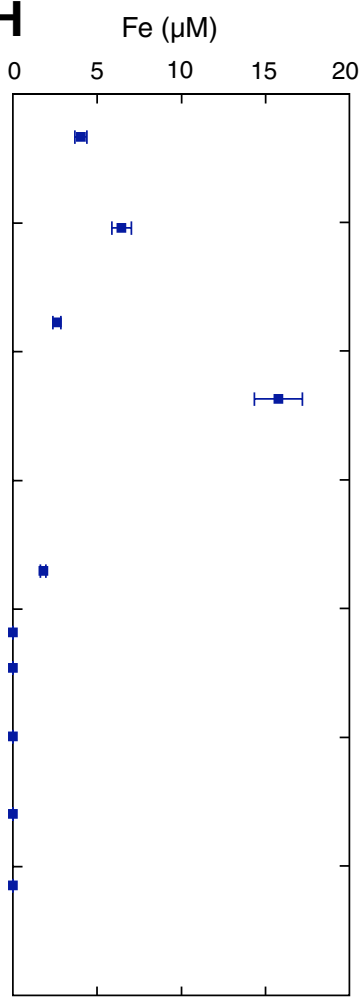
Table T1. Expedition 310 coring summary.

\begin{tabular}{crccc}
\hline Hole & $\begin{array}{c}\text { Number } \\
\text { of cores }\end{array}$ & $\begin{array}{c}\text { Cored } \\
(\mathrm{m})\end{array}$ & $\begin{array}{c}\text { Recovered } \\
(\mathrm{m})\end{array}$ & $\begin{array}{c}\text { Recovery } \\
(\%)\end{array}$ \\
\hline M0005A & 12 & 16.35 & 5.37 & 32.84 \\
M0005B & 8 & 12.35 & 9.24 & 74.82 \\
M0005C & 16 & 27.91 & 14.81 & 53.06 \\
M0005D & 36 & 79.17 & 51.35 & 64.86 \\
M0005E & 4 & 2 & 1.6 & 80.00 \\
M0006A & 4 & 2 & 1.55 & 77.50 \\
M0007A & 36 & 44.4 & 30.74 & 69.23 \\
M0007B & 36 & 47.93 & 27.02 & 56.37 \\
M0007C & 22 & 30.75 & 11.13 & 36.20 \\
M0008A & 19 & 38.7 & 9.49 & 24.52 \\
M0009A & 18 & 21.54 & 9.29 & 43.13 \\
M0009B & 18 & 26.29 & 17.42 & 66.26 \\
M0009C & 21 & 24.41 & 12.66 & 51.86 \\
M0009D & 25 & 43.31 & 23.62 & 54.54 \\
M0009E & 12 & 19.4 & 14.11 & 72.73 \\
M0010A & 20 & 33.25 & 10.02 & 30.14 \\
M0011A & 12 & 16.08 & 7.89 & 49.07 \\
M0012A & 19 & 32.3 & 8.37 & 25.91 \\
M0013A & 5 & 9.55 & 1.1 & 11.52 \\
M0014A & 14 & 18.61 & 8.65 & 46.48 \\
M0015A & 41 & 41.08 & 29.87 & 72.71 \\
M0015B & 38 & 40.12 & 28.83 & 71.86 \\
M0016A & 36 & 37.91 & 21.58 & 56.92 \\
M0016B & 24 & 27.62 & 14.31 & 51.81 \\
M0017A & 21 & 40.56 & 22.94 & 56.56 \\
M0018A & 22 & 40.05 & 24.63 & 61.50 \\
M0019A & 34 & 65.81 & 27.06 & 41.12 \\
M0020A & 25 & 41.83 & 29.47 & 70.45 \\
M0021A & 22 & 33.58 & 25.14 & 74.87 \\
M0021B & 20 & 32.21 & 21.12 & 65.57 \\
M0022A & 4 & 7.7 & 4.4 & 57.14 \\
M0023A & 16 & 31.36 & 24.21 & 77.20 \\
M0023B & 16 & 31.12 & 21.13 & 67.90 \\
M0024A & 16 & 31.85 & 26.67 & 83.74 \\
M0025A & 13 & 20.33 & 15.09 & 74.23 \\
M0025B & 13 & 19.4 & 13.81 & 71.19 \\
\cline { 2 - 5 } & 8 & 11 & 6.43 & 58.45 \\
\hline
\end{tabular}


Table T2. Location of description and measurements made during Expedition 310.

\begin{tabular}{ll}
\hline \multicolumn{1}{c}{ Shipboard DP Hunter, offshore Tahiti } & Onshore Science Party, Bremen \\
\hline $\begin{array}{l}\text { Core description: } \\
\text { Visual core description through plastic liner }\end{array}$ & Core description: \\
Core catcher description & Split-core visual core description \\
& \\
Core photography: & Core photography: \\
Core catcher photography & Full-core and close-up photography \\
& \\
Whole-core multisensor core logging: & Discrete sample index physical properties: \\
Density & Compressional P-wave velocity \\
Velocity & Bulk, dry, and grain density \\
Magnetic susceptibility & Water content \\
Electrical resistivity & Porosity and void ratio \\
& \\
Inorganic geochemistry: & Inorganic geochemistry: \\
pH & Dissolved cations \\
Alkalinity & Bromide, chloride, and sulfate \\
Ammonia concentration chlorinity & Dissolved phosphate \\
& Chlorinity \\
Microbiology: & \\
Activity testing by ATP monitoring & Microbiology*: \\
Exoenzymes activity & SEM analysis (including SEM-EDAX analysis) \\
Microscopy (DAPI staining) & Cultivation of microorganisms \\
& Culturing \\
Downhole logging: & \\
Optical imaging & Other: \\
Acoustic imaging & Thermal conductivity (where possible) \\
Borehole fluid temperature and pressure & Color reflectance of split-core surface at discrete points \\
Electrical conductivity & Continuous digital line-scanning of split-core surface \\
pH & X-ray fluorescence (14 samples from Hole M0008A) \\
Oxydo-reduction potential (Eh) & \\
Spectral natural gamma ray & \\
Induction resistivity & \\
Full waveform sonic & \\
Caliper & \\
\hline & \\
& \\
&
\end{tabular}

Notes: ${ }^{*}=$ Analyses conducted at the Swiss Federal Institute of Technology (ETH) Zurich, Switzerland, between the end of the offshore phase and the beginning of the Onshore Science Party. ATP = adenosine triphosphate, DAPI = 4',6-diamindino-2-phenylindole, SEM = scanning electron microscopy, $\mathrm{EDAX}=\mathrm{X}$-ray energy dispersive analyzer. 


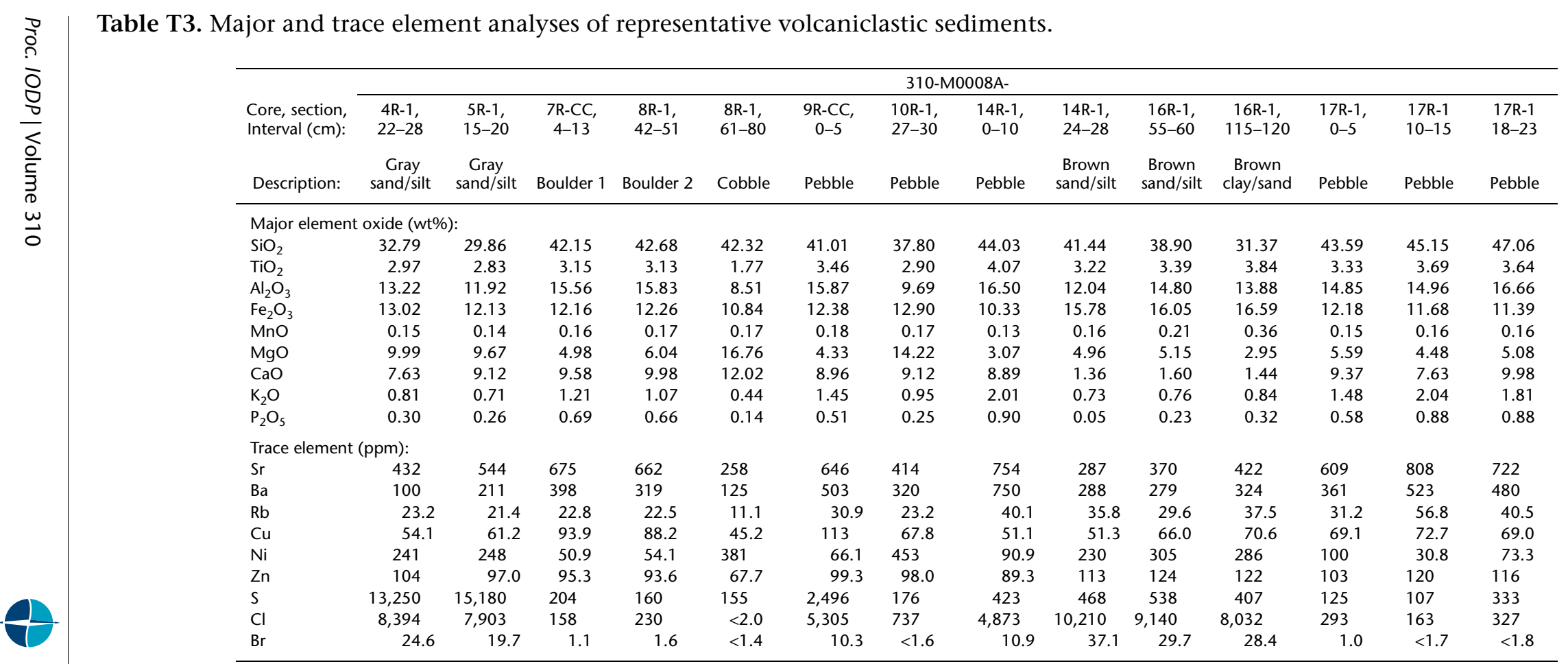

